\title{
Seismic imaging in the Krafla high-temperature geothermal field, NE Iceland, using zero- and far-offset vertical seismic profiling (VSP) data
}

\author{
Felix Kästner ${ }^{a, b, *}$, Rüdiger Giese ${ }^{b}$, Sverre Planke ${ }^{c, d}$, John M. Millett ${ }^{c, e}$, and Ólafur G. Flóvenz ${ }^{a}$ \\ a ÍSOR Iceland GeoSurvey, Grensasvegur 9, 108 Reykjavík, Iceland \\ ${ }^{\mathrm{b}}$ Helmholtz Centre Potsdam, German Research Centre for Geosciences GFZ, Telegrafenberg, 14473 Potsdam, Germany \\ c Volcanic Basin Petroleum Research (VBPR), Forskningsparken, 0349 Oslo, Norway \\ ${ }^{d}$ Centre for Earth Evolution and Dynamics (CEED), Oslo University, Oslo, Norway \\ e Department of Geology and Petroleum Geology, University of Aberdeen, Aberdeen, UK \\ * Corresponding author, contact: felix.kaestner@gfz-potsdam.de
}

\begin{abstract}
Among geothermal exploration methods, active surface seismic methods have played only a minor role to date. Especially in high-temperature volcanic systems, reflection seismic data often reveal poor delineation of volcanic features, due to the internal heterogeneity of volcanic sequences. To enhance the vertical resolution, one possibility is the application of downhole seismic methods like vertical seismic profiling (VSP). A test experiment was carried out in the Krafla hightemperature geothermal field, NE-Iceland, to assess the ability of VSP to image subsurface structures, such as fractures, zones of high permeability, magmatic bodies, and zones of supercritical fluids and steam. Logging in such hostile environments is technical challenging in many aspects, but mainly due to the high temperature impact on the downhole electronic components of the measuring equipment. This requires a thorough pre-examination and implementation of the measurement, especially to avoid delays and tool failures. This paper presents results of zero- and far-offset VSP data from the K-18 borehole from within the Krafla caldera, which reveal good correlation with the surrounding lithology. The raw three component seismic data display a good signal-to-noise ratio and dominant signal frequencies between 20 and $40 \mathrm{~Hz}$, down to c. 2200 mdepth, for air gun and explosive sources, respectively. A zero-offset source comparison was also conducted to assess the use of different impulsive sources for future VSP surveys in similar settings. By applying a standard VSP processing, we identified stratigraphic boundaries between lavas, hyaloclastites, and intrusions, which are in good agreement with existing well data. For the zero-offset VSP, both P- and S-wave velocity models were calculated and a depth-converted corridor stack was determined. In addition, multicomponent Kirchhoff depth migration and Fresnel volume migration were tested around the borehole. The 3D results are promising, but the specific shape and lateral extent of the reflectors could not be determined due to the restriction to only two sources and the insufficient spatial coverage (aperture). Our study demonstrates that vertical seismic profiles can clearly detect variations in the subsurface volcanic stratigraphy in hightemperature geothermal fields. A more detailed reservoir characterization can be achieved by further data integration, enhanced survey design including more source positions, and improved processing and imaging techniques, such as fullwaveform inversion.
\end{abstract}

Keywords: vertical seismic profiling; high-temperature; geothermal; Iceland; Krafla; IMAGE

\section{Introduction}

Although seismic applications for geothermal exploration have already been carried out (e.g., Hloušek et al., 2015; Riedel et al., 2015; Schmelzbach et al., 2016, and references therein), active seismic exploration methods still play a minor part, in particular, in high-temperature (HT) volcanic geothermal systems, which are often found along active tectonic rift zones exhibiting temperatures of 200 to $300^{\circ} \mathrm{C}$ in 1 to $2 \mathrm{~km}$ depth (Wohletz and Heiken, 1992). Seismic experiments within similar volcanic sequences have shown that seismic wave energy suffers from strong attenuation and scattering effects due to the inhomogeneous nature of volcanic formations which often include a complex combination of primary fragmentation, emplacement brecciation and cooling contraction jointing, along with secondary reworking, alteration and fracturing (Planke et al., 2000; Planke and Cambray, 1998; Planke and Flóvenz, 1996).

Mapping fractures and permeable zones is crucial in geothermal reservoir evaluation and for ensuring future production rates (e.g., Sausse et al., 2010). Surface exploration methods, such as magneto-telluric and wide-angle refraction profiling, despite their good lateral coverage, provide only a low vertical resolution. Geophysical logging, instead, has a high vertical resolution but only a limited depth of investigation, commonly of an order of a few decimeters. In addition, invasion and near-wellbore damage caused by the drilling process or heterogeneous volcanic facies may adversely affect well logs in volcanic settings (Millett et al., 2016). Vertical seismic profiles combine active seismic sources on the surface with seismic receivers lowered in a borehole, within the reservoir (Hardage, 2000). VSP therefore serves as a tie between surface methods (good lateral coverage, weak vertical resolution) and borehole logs (high vertical resolution, low lateral extent) (e.g., Christie et al., 1995; 
Hackert and Parra, 2002; Stewart, 2001). It can be used to image structures on reservoir scale, away from and below the borehole, which, for example, has successfully be shown in the Soultz-sous-Forêts geothermal system, France (Place et al., 2010, 2011).

In VSP but also in borehole geophysical logging in general, tools including sensitive sensors and electronics are constrained to a temperature and pressure range exposed over a certain period of time. A downhole geophone, as for instance used in this experiment, may withstand a maximum tool temperature of $150{ }^{\circ} \mathrm{C}$, over 6 to $8 \mathrm{~h}$. Higher temperatures or longer time periods can cause data transmission and recording errors, or even tool damages. Latest developments also provide tools up to $200^{\circ} \mathrm{C}$. Aggressive borehole fluid constituents (e.g., H2S, CO2) may also damage the O-rings which prevent fluid break-ins into the tool. Especially in geothermal context, this requires a sufficiently well-known temperature profile (log) at depth and in time. Temperatures have to be monitored and acquisition has to be interrupted if temperatures are too high, which result in delays and, ultimately, additional costs. Alternatively, the increasing development of the distributed acoustic sensing technology has also shown promising results in the field of geothermal exploration (e.g., Reinsch et al., 2015). However, for hanging cables, which are not cemented behind the casing, these methods are not favorable due to low signal-to-noise ratios.

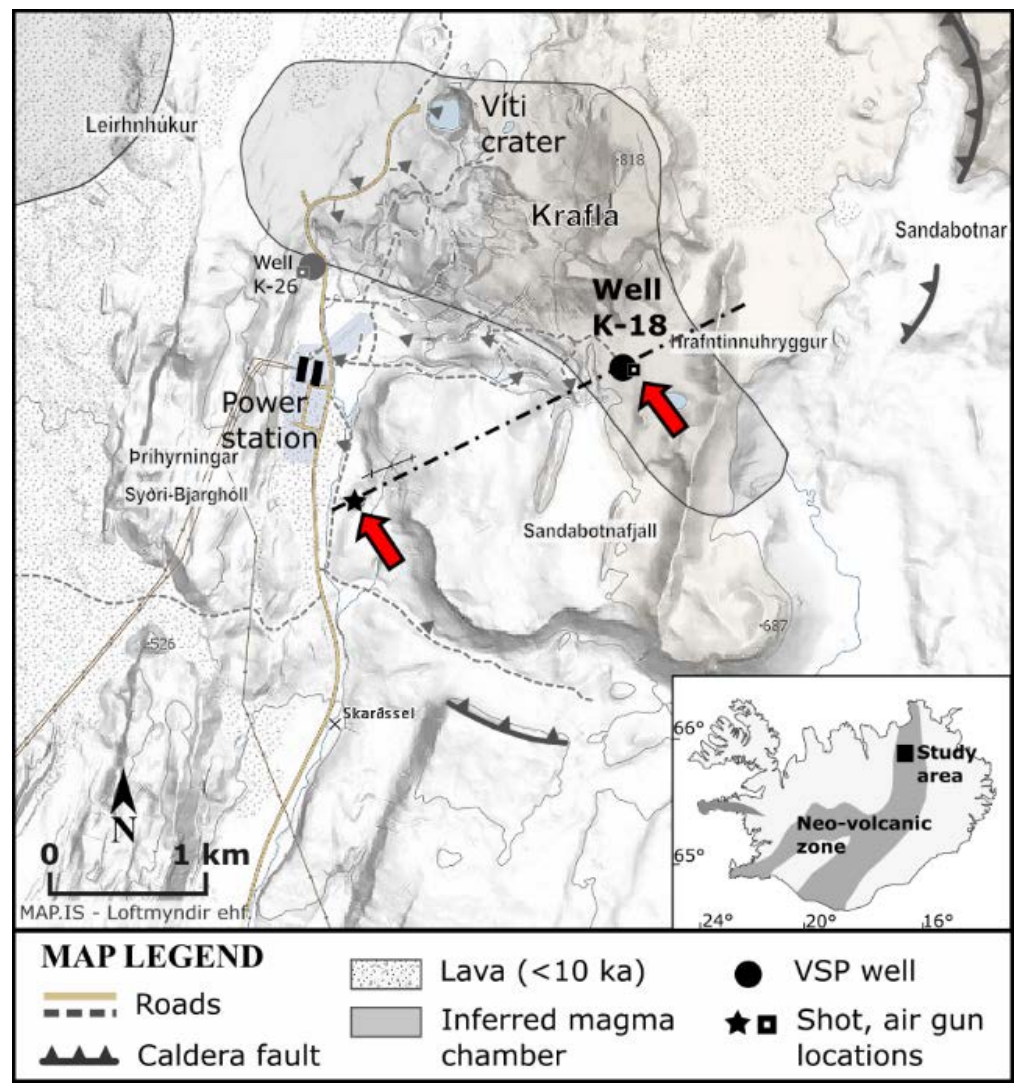

Figure 1. Map showing the location of the VSP experiment carried out in the Krafla geothermal field, NE Iceland (inlay). Arrows mark the zero- and far-offset VSP source locations presented in this study. Dashed line: projection of the lithological cross section and image grid for migration.

The applicability of VSP as a method for subsurface mapping in geothermal volcanic environments is investigated by the European Union's project IMAGE ${ }^{1}$ (Integrated Methods for Advanced Geothermal Exploration). In this regard, the Krafla hightemperature geothermal field (Fig. 1) provides a suitable test site because of fairly good knowledge about the subsurface geology including potential, shallow zones of steam and magma. Among information from $>40$ wells and surface exploration work, it also offers viable conditions (well access, cooling of the wells, personnel infrastructure) for a VSP experiment within the time and cost constraints of the project. The geothermal field is located directly on top of the onshore active-volcanic rift system of the Mid-Atlantic Ridge, in northeastern Iceland (Thordarson and Höskuldsson, 2002, chap. 7). The VSP experiment that forms the basis of this study comprises the first of its kind carried out in a high-temperature geothermal field on Iceland. Planke and Flóvenz (1996), however, describe a previous VSP survey in a low-temperature field in Eyjafjardar where they studied the seismic velocity and anisotropy from two low-temperature wells. Other VSP surveys successfully carried out in geothermal fields, outside of Iceland, are documented, for example, by Cameli et al. (1995), Lorenzo et al. (2015), Nakagome et al. (1998), Place et al. (2011), and Riedel et al. (2015). In a more recent study, Reiser et al. (2017) gained valuable insights about the design of VSP experiments to image fracture zones over hard-rock basement geothermal environments. 
One important objective of the IMAGE project was to develop and test exploration methods such as the VSP method as a complementary, active seismic exploration method, in magmatic environments. Herein, we investigate the acquisition of VSP data with an air gun and explosive source, the expected signal quality, and its ability to get proper reflections from the subsurface. The investigated data are based on the VSP-test experiment carried out at Krafla in May and June 2014. More precisely, we discuss three-component zero- and far-offset data from the K-18 borehole and, furthermore, test the ability to image reflections away and ahead from the borehole using Kirchhoff depth migration (KDM) and Fresnel volume migration (FVM). VSP surveys in general require repeatable sources which can be excited several times, without changing the signal phase and amplitude. Active seismic for geothermal exploration may also face logistical problems such as the proximity to plant facilities or surface conditions (e.g., hot springs, borehole cellar, snow etc.). Therefore, two additional zero-offset sources (detonating cord, shot-hole explosive) were tested in a source comparison, in order to assess their potential for future VSP surveys.

The here presented data and resulting processing involving 3-D migration serve as a first imaging test experiment as part of the IMAGE project. With respect to available costs and the difficult area, the experiment was limited to two major zero-offset shot surveys and several low-priority offset profiles having only a fraction of the receiver coverage. Therefore, to provide a first feasibility study, we selected the two most representative shots based on the highest depth coverage along the borehole and the best signal-to-noise ratio of the raw data. Our results focus on the basic imaging potential in the scope of this particular geological and experimental setting.

\section{Geological setting}

The study area is part of the Krafla volcanic system, located in the neovolcanic zone in northeast Iceland (Fig. 1). Being part of the onshore extension of the Mid-Atlantic Ridge, this active spreading zone is characterized by several N-S elongated volcanic systems, each associated with a central volcano and swarms of linear volcanic fissures composed of tensional cracks, normal faults, and graben structures (Thordarson and Höskuldsson, 2002). The Krafla volcanic system is characterized by a $\mathrm{N}$ $\mathrm{S}$ transecting, 80-100 km long fissure swarm and an 8-10 km wide caldera, mostly filled with volcanic sediments. In the past ten thousand years, this fissure system was shaped by several rifting episodes (Hjartardóttir et al., 2012), the latest in the years 1975-1984, and known as the Krafla fires.

The structure of the lithosphere in Iceland has been studied by many refraction and wide-angle seismic profiles, predominantly in 1980s and 1990s (e.g., Flóvenz and Gunnarsson, 1991; Menke et al., 1998; Staples et al., 1997). These studies essentially show that the Icelandic crust divides into an upper and lower crust characterized by substantial differences in the P-wave velocities. Especially, with respect to northeast Iceland and its active rift zones, the velocity structure of the upper crust is highly inhomogeneous. Regional variations in P-wave velocities reflect mineralogical phase changes associated with alteration, which correlate with higher temperatures. As a result, higher velocities are often observed within the geothermal reservoir, due to the recrystallization (alteration) of secondary minerals in the pore and fracture space. Locally, shallow and young lava piles are associated with low P-wave velocities and high porosities resulting in strong wave attenuation and scattering (Flóvenz and Gunnarsson, 1991).

The Krafla high-temperature geothermal field is located on the southeast flank of Mt. Krafla (818 $\mathrm{m}$ a.s.I.). Within the geothermal system, alternating layers of subaerial basaltic lava flows and subglacial erupted hyaloclastites overly a gabbroic intrusive basement (Fig. 2). The displayed cross section, Fig. 2, is based on implementations of research and drilling results of the Krafla geological and reservoir models which have been revised several times (e.g., Mortensen et al., 2009; Weisenberger et al., 2015; porsteinsdóttir, 2017). The underlying geological model compromises surface observations (e.g., outcrops, alteration zones, faults, and fissures) interpolated into the subsurface mainly by linking borehole observations (ditch cuttings, wireline data, image logs) and geophysical prospection data (e.g., MT, gravity). Geothermal surface manifestations and zones of hydrothermal alteration are the most obvious evidence of a deeper-rooted geothermal activity (Wohletz and Heiken, 1992). S-wave shadows directly beneath the Krafla central volcano have been used to infer a magma chamber at 3-7 km depth (Einarsson, 1978). Studies from refraction and passive seismic (Brandsdóttir et al., 1997; Staples et al., 1997; Tang et al., 2008), as well as recent magnetotelluric and micro-seismic studies (Onacha et al., 2005) further support the presence of a shallow magma chamber which is divided into a western and an eastern part, with a top interface at about 2.5-3 km depth. 


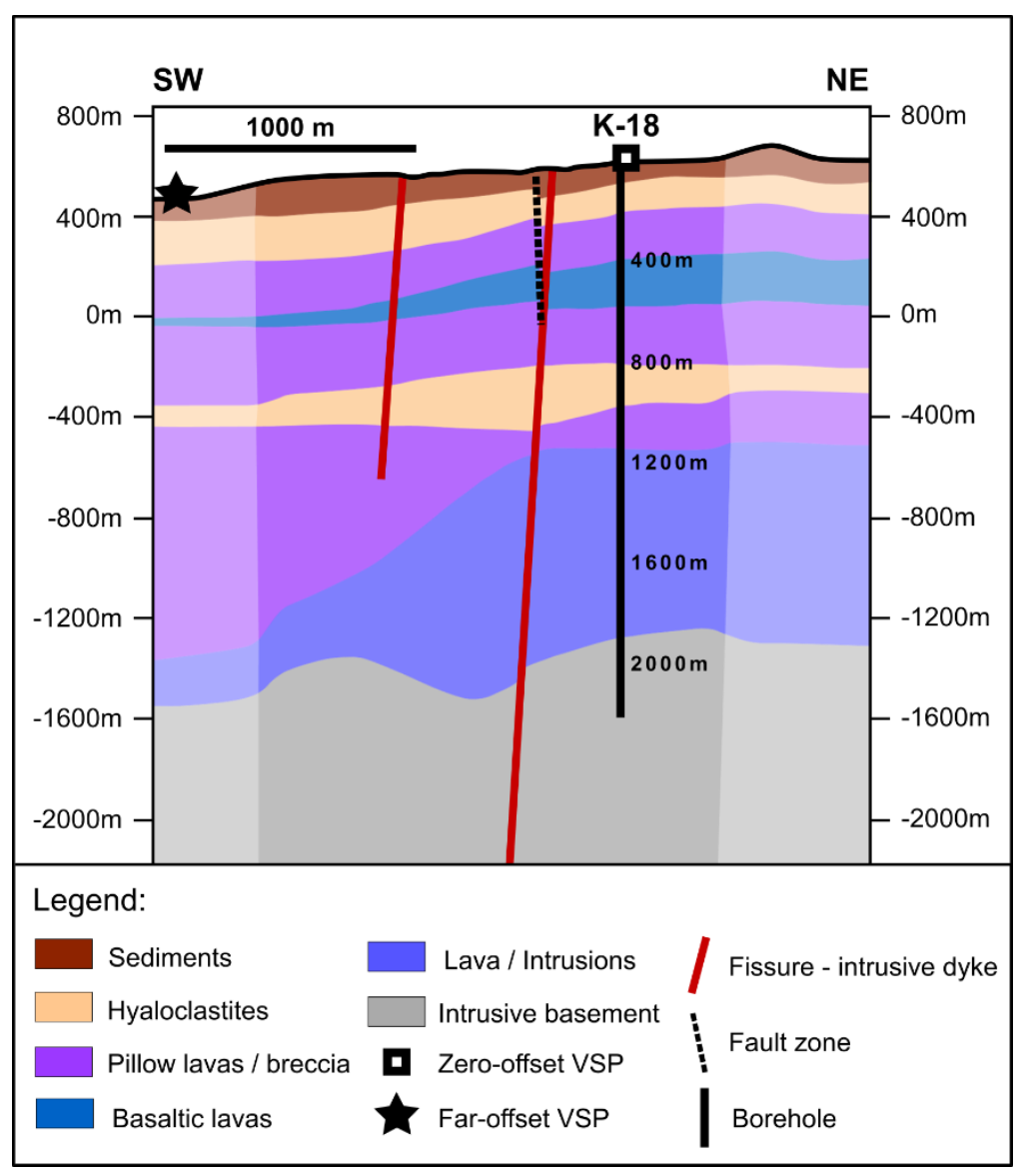

Figure 2. Lithological cross section (cf. Fig. 1) derived from static, data-driven stratigraphic model based on borehole data and geological mapping (fractures). Model is based on borehole and surface data interpolated within a 500-m radius around the K-18 borehole, and extrapolated outside of it (bright areas). Adapted from porsteinsdóttir (2017, personal communication).

The Krafla geothermal power plant was built in several stages starting in 1974 . Today, it produces $60 \mathrm{MWe}$ of steam from 44 wells of about $2 \mathrm{~km}$ depth (Nielsen et al., 2000). From early modelling studies, Bodvarsson et al. (1984) have determined that the Krafla reservoir is mainly separated in two aquifers. The water dominated upper reservoir $(1-2 \mathrm{~km})$ reaches temperatures between 180 and $250{ }^{\circ} \mathrm{C}$ whereas the lower reservoir $(\mathrm{N} 2 \mathrm{~km})$ is steam dominated and provides temperatures of $350{ }^{\circ} \mathrm{C}$ or higher. More recent and revisited conceptual models of the reservoir (Mortensen et al., 2009; Weisenberger et al., 2015) indicate a strong heterogeneity throughout the entire geothermal system. Freshly intruded magma into the IDDP-1 borehole (Elders et al., 2011) and the recent Krafla fissure eruption highlight a frequently active area with a primary heat source from current and recent magma intrusions both at depth and into the shallow crust.

\section{Methods and data acquisition}

Vertical seismic profiling uses active seismic sources on the surface and receivers placed in a borehole to explore and image structures of the subsurface. Having a long tradition in the oil and gas industry, VSP results are often compared with surface reflection seismic profiles and geological logs (Chopra et al., 2002; Poletto et al., 2013; Stewart, 2001). Due to its geometry, with receivers at depth, smaller Fresnel zone, and generally wider frequency bandwidth, VSP provides a better resolution than surface seismic data (Payne et al., 1994). Another advantage of VSP is the possibility to distinguish between down- and upgoing wavefield. In zero-offset vertical seismic profiling, where the source at the surface is closest to the well, the downgoing wavefield is historically used to derive seismic properties such as velocity profiles, frequency content, or attenuation directly along the well path, at depth. Upgoing waves, instead, can be used to identify reflections from interfaces or lithological boundaries, which later are migrated and, if available, are sliced into surface seismic reflection profiles.

\subsection{Survey geometry}

The here presented VSP data were acquired during a two-week survey in Krafla, NE-Iceland, in May and June 2014. We discuss a subset of the data comprising the zero- and far-offset VSP recorded in well K-18 (Fig. 1). A complete field report is provided by Halldórsdóttir et al. (2014), prepared for IMAGE. 
The K-18 borehole was drilled down to $2215 \mathrm{~m}$ depth (below ground), in the southeast of the Suđurhlídar well field in 1981. It marks the easternmost boundary of the Krafla geothermal system. Being non-productive providing relatively low temperatures, the well now is mainly used for exploratory purposes by Landsvirkjun, the operator of the Krafla geothermal field. The borehole was drilled vertically having a slight deviation of only about 1 to $2^{\circ}$ (Árnadóttir, 2014). Thus, the maximum deviation is $<20 \mathrm{~m}$, which justifies the usage of non-gimballed geophones. Unless no additional fluid is pumped down the borehole, the temperature at the bottom will increase to about $185^{\circ} \mathrm{C}$, although the surrounding formation temperature is around $300{ }^{\circ} \mathrm{C}$. This is explained by some minor feed zones at circa 750 and $900 \mathrm{~m}$ depth causing a down-flow inside the borehole. A detailed volcanic facies interpretation of ditch cuttings and wireline log analyses from the K-18 borehole is given by Millett et al. (2018). The horizontal distance (offset) of the source to the wellhead is $29 \mathrm{~m}$ for the zero- and $1904 \mathrm{~m}$ for the far-offset VSP, respectively. Due to the local topography, the far-offset source point is located about $170 \mathrm{~m}$ below the wellhead of $\mathrm{K}-18$, whereas the zero-offset source point is at the same level as the wellhead. Finally, eight auxiliary threecomponent $28 \mathrm{~Hz}$ geophone receivers were deployed on the surface, inline, between the wellhead and the zero-offset air gun pit, for comparison with the down-hole recordings.

\subsection{Sources and receivers}

For the zero-offset VSP, an air gun (type Bolt 1900LL-PGS) was hung into an artificial water pit of $4 \mathrm{~m}$ by $8 \mathrm{~m}$ in extent and 3 $\mathrm{m}$ depth, and was used for the seismic signal generation (Fig. 3). With a $40 \mathrm{~m} 3$ chamber volume and a working pressure of 130-140 bar, this yielded a bubble period of about $50 \mathrm{~ms}$ and dominant frequency of $20 \mathrm{~Hz}$. For the far-offset VSP, shots of $1 \mathrm{~kg}$ of dynamite explosive were fired in a $4-5 \mathrm{~m}$ deep natural pond.

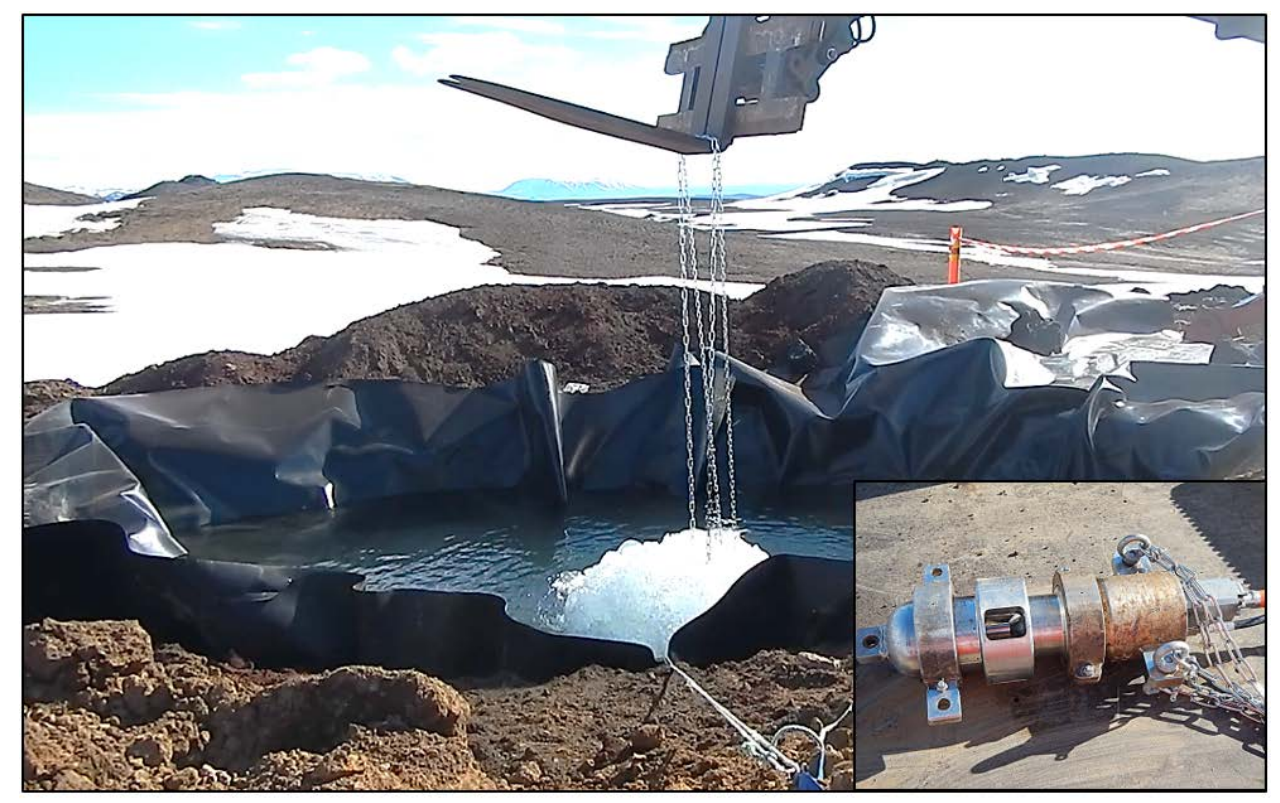

Figure 3. Water-filled zero-offset source pit with mounted air gun (lower right corner). Bubbles emerge at the water surface, shortly after source excitation.

For the source comparison, two additional impulsive sources were tested: (1) a $50 \mathrm{~m}$ long detonating cord (type Nitrocord10) carrying $500 \mathrm{~g}$ of dynamite, and (2) a single-charge shot-hole explosive (charge: $250 \mathrm{~g}$ ). The detonating cord was lined radially, to the south-east, about $50 \mathrm{~m}$ away from the borehole, on snow. This was deemed to be most suitable according to the available space and well-head distance. The dynamite explosive, instead, was lowered into a $9 \mathrm{~m}$ deep shot hole, which was drilled and cased previous to acquisition, about $30 \mathrm{~m}$ south-east of well K-18. In total, we compared four source configurations for the zero-offset VSP: (1) single-fold air-gun shot, (2) ten-fold air-gun shot, (3) shot-hole explosive, and (4) line-source explosive. In each case, we used the vertical geophone components from a single tool position, thus, yielding six traces with a $10-\mathrm{m}$ trace spacing, between 700 and $750 \mathrm{~m}$ depth.

A multi-channel geophone chain (type Sercel SlimWave) with 17 levels, each equipped with three mutually orthogonal $15 \mathrm{~Hz}$ geophones, was lowered into the borehole. With it, data were recorded between 10 and $2180 \mathrm{~m}$ (below ground level), with a regular, $2.5 \mathrm{~m}$, and irregular, 7.5-10m, receiver interval for the zero and far offsets, respectively. Each of the deployed geophones were equipped with a caliper arm to fix them mechanically to the borehole wall and to ensure a good coupling between the receiver units and the rock formation. The maximum working temperature of the chain's downhole electrical components was $150^{\circ} \mathrm{C}$. 


\subsection{Data acquisition}

While running down into the borehole, the chain was stopped at defined depths and the geophone levels were mechanically coupled to the borehole wall. Zero-offset air-gun and far-offset dynamite shots were carried out sequentially (i.e., in series) while the geophone levels remained coupled to the borehole wall. The excited down- and upgoing wavefield, which have been reflected, refracted, and scattered by local inhomogeneities, were recorded by the receivers inside the borehole. At each downhole position, up to 15 air-gun shots were recorded, which, in the later processing, were stacked (i.e., summed vertically) for signal enhancement.

The well was cooled by regularly injecting water for six weeks previous to the survey. During acquisition, the tool-internal temperature sensors were used to monitor the temperature inside the well. Due to the very high noise level associated with the injection, the cooling had to be stopped completely during each measurement. Occasionally, when the temperature exceeded a pre-defined threshold of $150^{\circ} \mathrm{C}$, related to the geophone operating limits, the acquisition was interrupted. The tool was then moved to cooler well regions determined from earlier temperature logs, and water was injected to cool the well again. As a result, temperatures were generally maintained between 80 and $150{ }^{\circ} \mathrm{C}$.

Figs. 4 and 5 show the three-component seismic records for both zero and far-offset shots, respectively. Their raw, singletrace amplitude spectra are shown in Fig. 6 . Here, for display purposes, some basic processing, such as trace sorting, bandpass filtering, horizontal component rotation, and vertical stacking has already been applied. The individual processing steps and seismic records are described, in detail, in the following section.
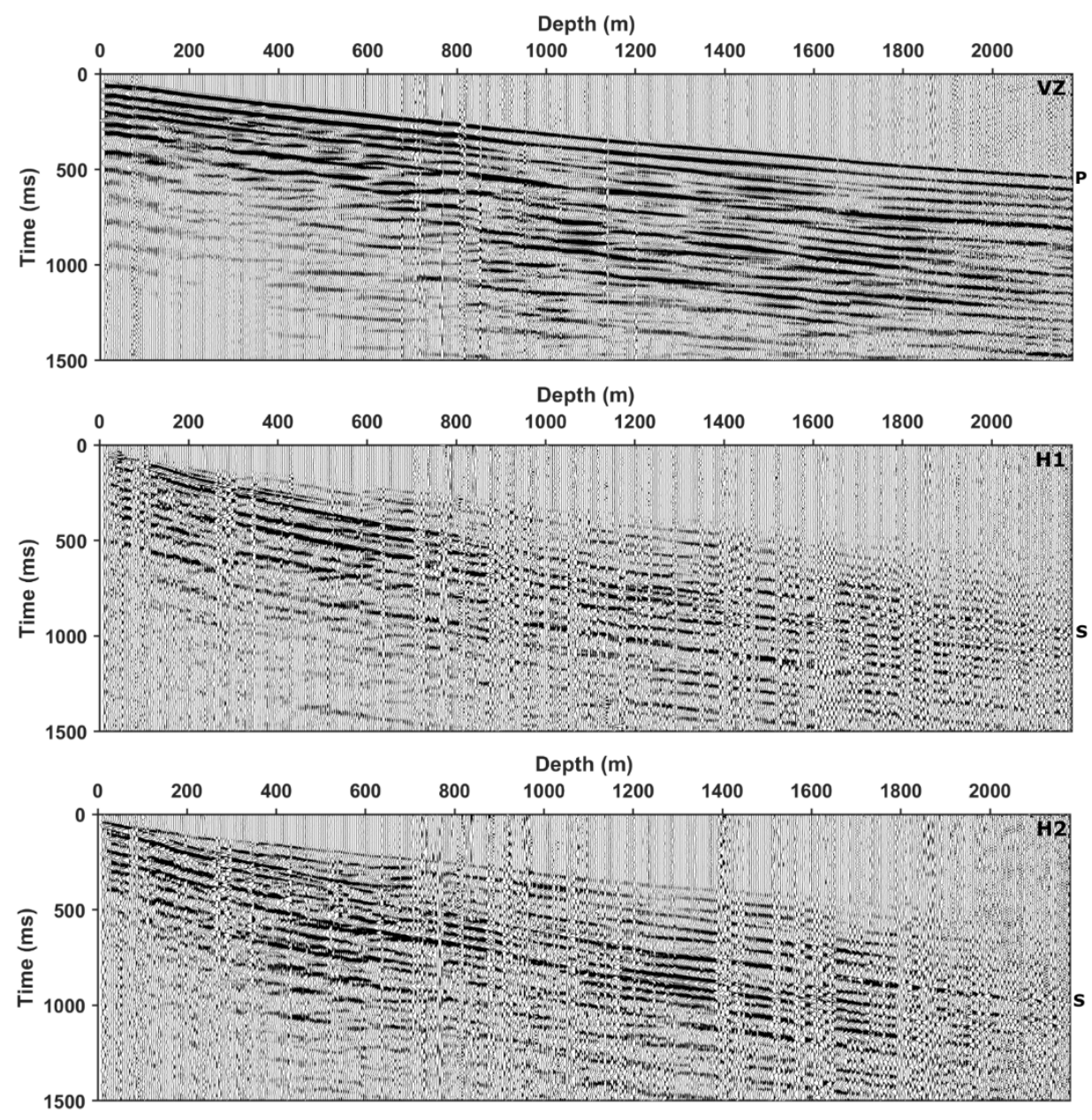

Figure 4. Zero-offset three-component seismograms recorded in well $K$-18. Records are trace normalized band-pass filtered and the horizontal components are rotated: VZ - Vertical component, H1 - horizontal component within the far-offset sourcereceiver plane, $\mathrm{H} 2$ - perpendicular to that plane. $P$ - and S-wave first arrivals are designated with their respective letter. 

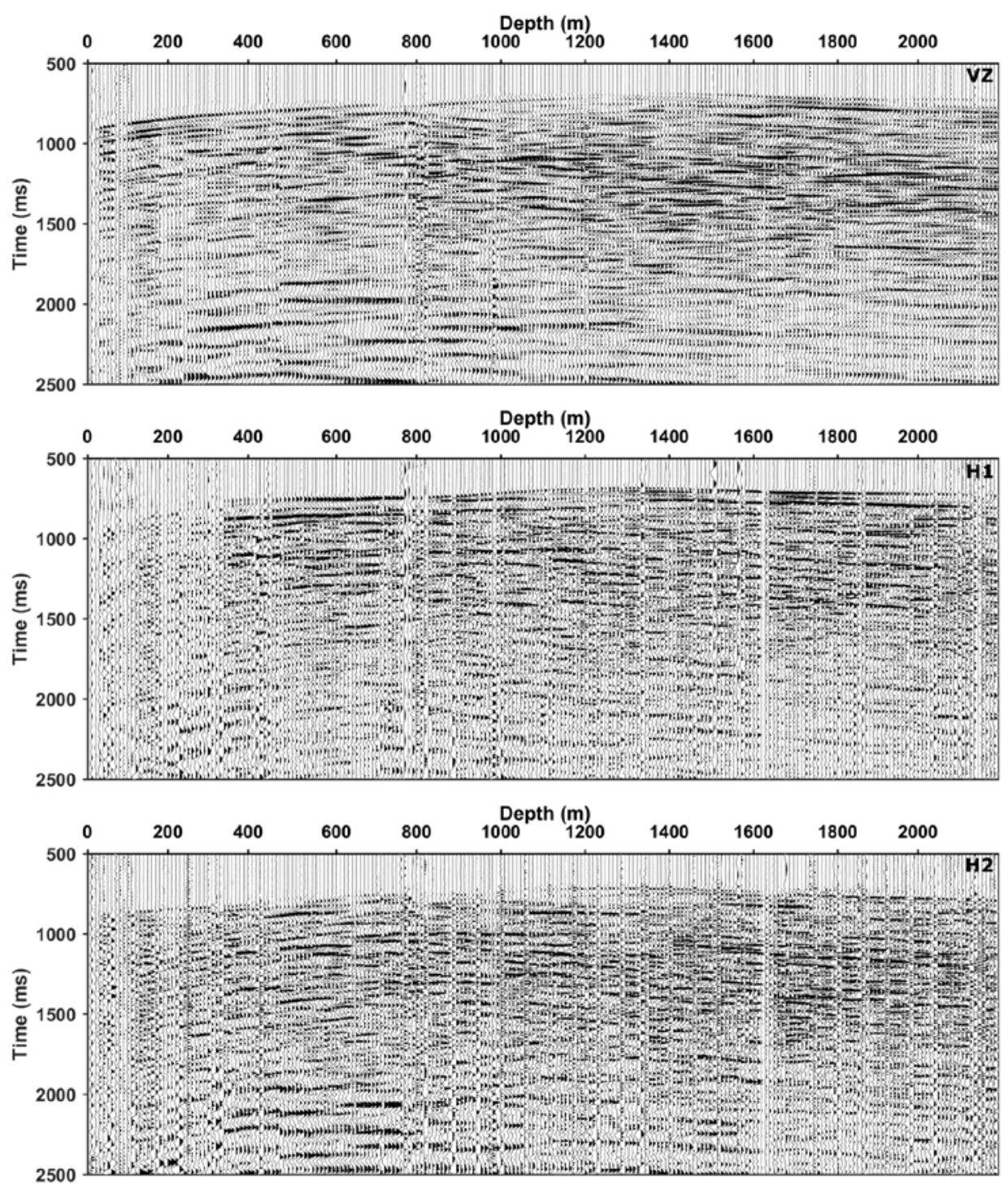

Figure 5. Far-offset three-component seismograms recorded in well K18. Records are trace normalized band-pass filtered and the horizontal components are rotated: VZ - Vertical component, $\mathrm{H} 1$ - horizontal component within the far-offset sourcereceiver plane, $\mathrm{H} 2$ - perpendicular to that plane.
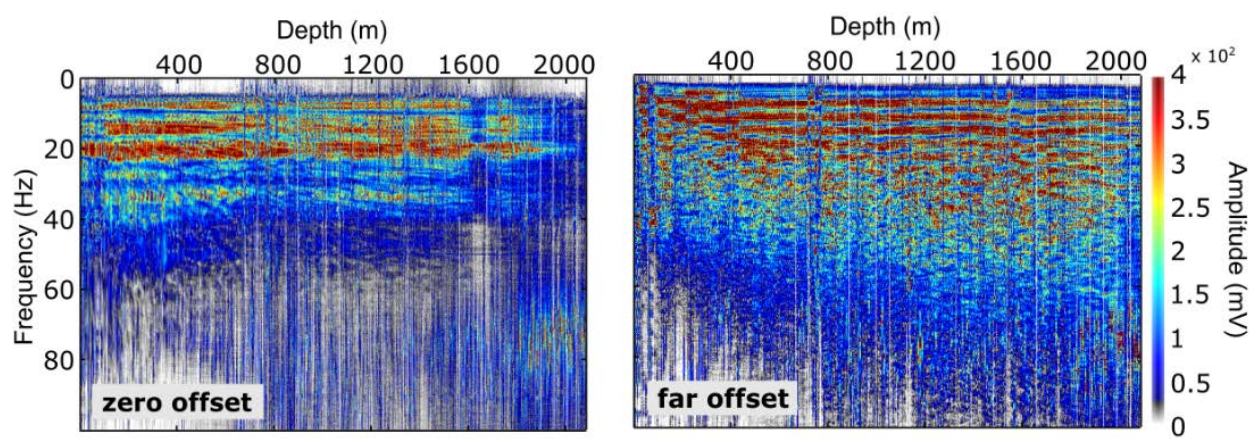

Figure 6. Frequency content (trace display) of the zero- and far-offset VSP using, respectively, an air gun and dynamite explosives.

\subsection{Seismic processing}

Seismic data processing, in general, is applied to improve the signal-to-noise ratio and to facilitate the interpretation of the seismic record (Sheriff, 2002). Here, for the VSP data, we particularly want to emphasize and retain primary reflections (direct upgoing waves) which are commonly masked by the direct downgoing wavefield. Seismic processing was carried out as part 
of a master's project at the Helmholtz Centre Potsdam, GFZ (Kästner, 2015). The processing involved processing procedures for one- and three-component VSP data, for example described by Hinds et al. (1996). The processing sequence is separated into pre-processing and main processing workflows (Fig. 7). The former comprises quality control, trace sorting, and editing tasks as well as the stacking at constant receiver depths of the zero-offset data.

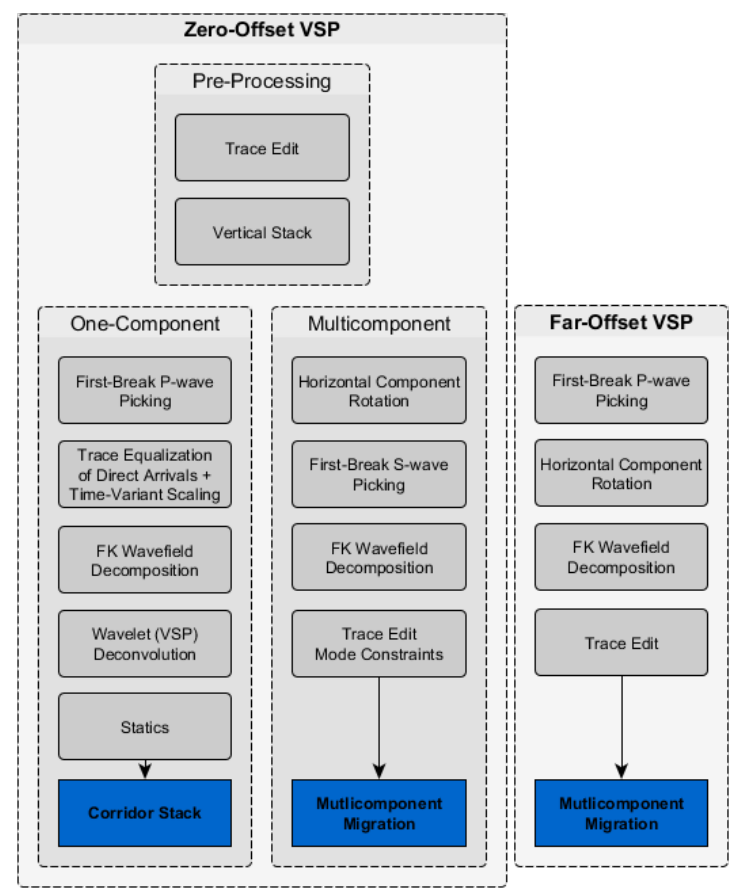

Figure 7. Flowchart showing the applied processing steps and data preparations.

The zero-offset VSP processing sequence further splits into two distinct workflows. The first workflow only includes the vertical component data, to calculate the corridor stack and to compare it with other well data such as lithology, natural gamma, and neutron-neutron logs. Initially, first breaks were picked manually along the downgoing first-arrival times. Later, these times were used to calculate interval velocities and one-dimensional velocity profiles for compressional $(\mathrm{P})$ and shear (S) waves along the borehole. The up- and downgoing wavefield was then separated using a quadrant attenuation in the frequency-wavenumber (FK) domain. The resulting upgoing wavefield was deconvolved using the downgoing wavefield as an inverse filter operator, often referred to as VSP deconvolution (Hinds et al., 1996). Each trace of the deconvolved upgoing wavefield was then shifted to its doubled first-arrival time, intending primary reflections to be horizontally aligned. These time-shifted traces were all stacked over a data window (i.e., outer corridor) of $200 \mathrm{~ms}$, starting from the first-break times in order to exclude most of the potential multiples. Finally, the stacked trace (corridor stack) was converted from time to depth using the known P-wave velocity profile yielding the depth-converted outside corridor stack for the one-component zerooffset VSP.

\subsection{Seismic migration}

Seismic migration can be used to map reflection events to their true subsurface positions (Hagedoorn, 1954). A seismic reflection element in a recorded seismogram (offset-time domain) is transformed, i.e. migrated, to a reflector element in the underground (space domain). Migration increases the lateral resolution of a seismic record by collapsing diffraction signals and focusing them at their local scatterer. This improves the accuracy of the seismic image and facilitates its geologic interpretation (e.g., Buske, 1999). Nowadays, a large number of different migration methods exist. They are distinguished in ray-based methods and wave-equation-based methods (Berkhout, 1982). Gray et al. (2001) give a summary of the most common migration methods, their application, and discuss particular merits and problems.

As part of the multicomponent processing flow (Fig. 7), the shot data was prepared for three-component seismic migration. During acquisition, the geophone levels experienced (e.g., due to cable seasoning) a quasi-random, axial rotation through their movement within the borehole. As a result, the horizontal geophone components of adjacent levels are not equally aligned, and the seismic signals may appear incoherent on the seismic record. Therefore, the horizontal geophone components had to be rotated in order to be equally aligned all in the same direction, towards ( $\mathrm{H} 1$ in Figs. 4 and 5) and perpendicular ( $\mathrm{H} 2$ in Figs. 4 and 5 ) to the vertical plane containing the $\mathrm{K}-18$ borehole and the zero- and far-offset source 
location, respectively. The used rotation procedure is based on a polarization analysis represented by particle-motion diagrams (DiSiena et al., 1984; Hendrick and Hearn, 1999). The rotation angles are determined by solving a least-square fitting problem of the samples of two corresponding components. Thus, the actual azimuthal orientation is determined by means of the two respective horizontal receiver components for each receiver position separately. Later, during migration, this information is essential to correctly back-propagate reflections to their origin in the three-dimensional space. For the vertical borehole the orientation of the vertical component is always known, parallel to the borehole axis. It also must be noted, that for this process we assume the waves to travel within the source-receiver plane and being fairly linearly polarized. This, however, cannot be completely ensured by such a scattering medium.

In a last preparation step, we additionally tried to reduce potential cross-talk effects in the zero-offset data which result from interfering and converted $\mathrm{P}$ - and S-wave modes. By assuming nearly vertical and parallel $\mathrm{P}$ - and S-ray paths along the borehole, we used median filtering (dip filtering) to remove $\mathrm{P}$ - and S-wave reflection modes based on their specific velocities in the time-offset domain. That is, depending on the wave mode to be removed, the wavefield was aligned (shifted in time) and subsequently filtered using either P- or S-wave first-arrival times. Different mute gates were applied to prevent interference from later wave modes. Fig. 8 shows the previously described concept schematically. So, in total, three multicomponent input shot gathers were created for migration: (1) standard processed zero-offset, (2) standard processed far-offset, and (3) mode-constrained zero-offset gather.

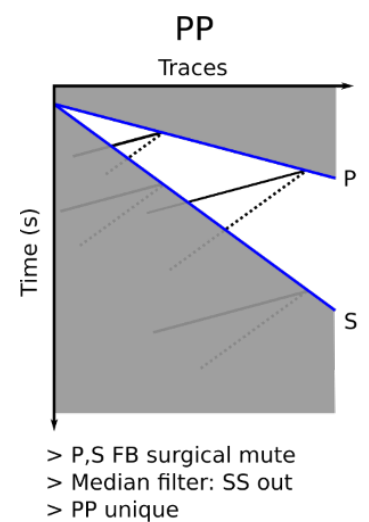

SS

Traces

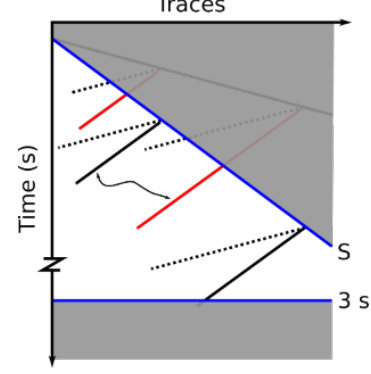

$>$ S, 3 s surgical mute $>$ Median filter: PP out $>$ SS+PS ambiguious

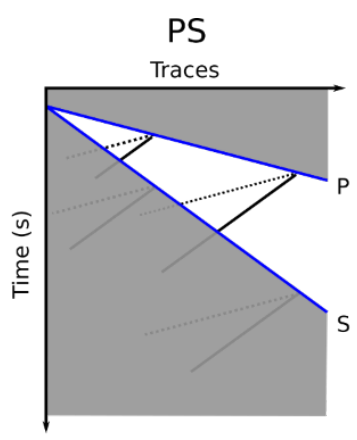

$>$ P,S FB surgical mute $>$ Median filter: PP out $>$ PS unique

SP

Traces

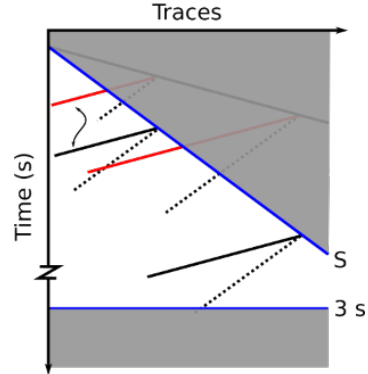

$>$ S, 3 s surgical mute

$>$ Median filter: PP out

$>\mathrm{SP}+\mathrm{PP}$ ambiguious

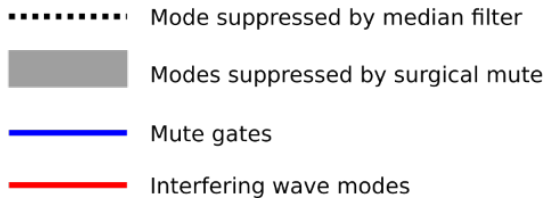

Figure 8. Schematic showing different procedures to extract certain wave modes for the multicomponent migration of the zero-offset VSP. PP: direct P-wave reflections; SS: direct S-wave reflections; PS, SP: P-to-S and S-to-P converted reflections.

In this paper, we tested two migration methods based on the Kirchhoff depth migration (Schneider, 1978) to image multicomponent VSP data. In theory, being a wave-equation method, the Kirchhoff migration relies on an integral solution of the wave equation (e.g., Biondi, 2005). In practice, travel times are calculated and amplitudes are summed (stacked) along diffraction curves. Thus, a migrated image in 2-D is constructed by the constructive interference of contributing diffraction curves. It provides good imaging results for geometries with dense source-receiver coverage by constructive interference of isochrones, namely, surfaces of equal reflection times. However, in areas of low source-receiver coverage, such as in limited VSP experiments, images often suffer from artifacts or migration noise (Lüth et al., 2005). Alternatively, modified migration 
schemes are available to constrain the migration operator and to provide focused images even for sparsely sampled shot geometries. As shown by Lüth et al. (2005) for multicomponent and Buske et al. (2009) for single-component seismic data, Fresnel volume migration can be used to enhance the image in limited seismic reflection experiments by restricting the migration operator to the physically defined Fresnel volume of the specular ray paths.

In the scope of testing the ability to migrate single-shot VSP data, we used a constant velocity model $(\mathrm{Vp}=4600 \mathrm{~m} / \mathrm{s}$ and $\mathrm{Vs}$ $=2700 \mathrm{~m} / \mathrm{s}$ ) according to the mean value of the $\mathrm{P}$ - and S-wave velocities derived from the zero-offset first-arrival times. The model dimensions are 3000, 1000, and $4000 \mathrm{~m}$ in the $\mathrm{x}-, \mathrm{y}-\mathrm{z}$-directions, respectively, where the $\mathrm{x}$-direction is in-line with the well and the far-offset source location, Fig. 9. We first tested to migrate each wave mode (pure $P$, pure $S$, and mixed $P$ and $S$ ) separately and consequently summed them for a final, enhanced mode-stacked migration image.

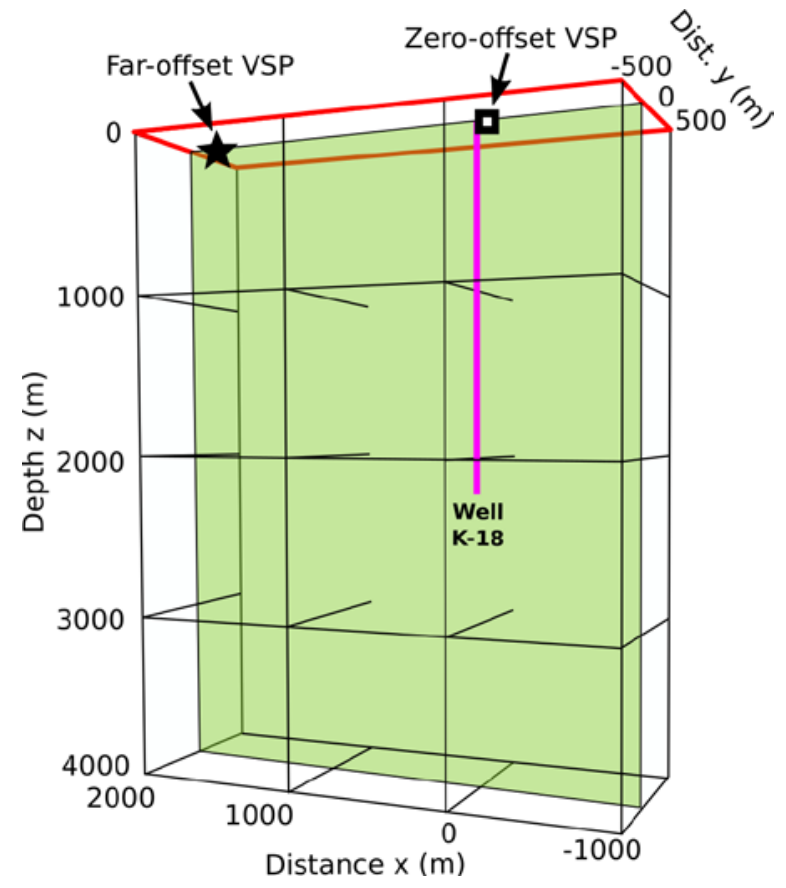

Figure 9. Geometry of the image volume used for multicomponent VSP migration (Figs. 15 and 16). Central vertical plane (green) is in line with the well and the far-offset shot position and indicate the location of the image sections shown in Fig. 15.

The processing was done using the ProMAX Seismic Processing Software by Landmark. Seismic migration was performed using the Integrated Seismic Imaging System (program codes for the 3D imaging of discontinuities from seismic records around tunnels and boreholes), which has been developed at the Helmholtz Centre Potsdam, Germany (Borm and Giese, 2003).

\section{Results}

Three-component vertical seismic profiling data were successfully recorded in well K-18 of the Krafla high-temperature field. In terms of signal-to-noise ratio, zero- and far-offset data show a similar, good overall quality, with clear and coherent first arrivals at almost all depths.

The zero-offset seismograms (before wavefield decomposition) show strong direct P-wave arrivals on the vertical component and direct S-wave arrivals on the two horizontal components (Fig. 4). Some P-wave energy, however, is distributed on the horizontal components, too. Several transecting primary reflections, which are waves travelling upwards after being reflected at an interface, are seen in the uppermost $1 \mathrm{~km}$. They are producing a typical pattern of overlapping up- and downgoing arrivals. Beside $\mathrm{P}$ - and S-reflected waves, we also identified converted and refracted wave modes by their apparent velocity (i.e., changing dip within the seismic record). In the following, we designate reflected P-wave energy as PP, S-waves as SS, and converted P- and S-waves as PS and SP, respectively. The far-offset VSP shot gather, as shown in Fig. 5 (before wavefield decomposition), shows a more complex wavefield, which is likely dominated by wide-angle and out of- plane reflections, as well as diving waves caused by a high vertical velocity gradient and large horizontal offset (ca. circa $2 \mathrm{~km}$ ). Furthermore, we expect a strong scattering effect by a main fault/fracture zone indicated by the surface geology, transecting the far-offset profile. Thus, reflections and their origin could not be identified only from the seismograms. Strong, coherent seismic signal energy, however, is visible on all three components, along the first arrivals, which are clearly seen between 500 and $1800 \mathrm{~m}$ depth. Beyond, onsets become more unclear due to interference with later arrivals from refracted or reflected waves. The 
earliest arrivals, where the P-wave ray path is almost horizontal, are indicated by vanishing amplitudes on the vertical receiver components at about $1300 \mathrm{~m}$ depth. Reflections below $1300 \mathrm{~m}$ depth appear weaker over all times, which might mark the region of the intrusive, rather homogenous basement.

The frequency content of the unprocessed zero-offset shot gather provides signal frequencies up to $40 \mathrm{~Hz}$ with a dominant frequency at about $20 \mathrm{~Hz}$, as expected for the applied air gun source (see Fig. 6). Despite the larger source offset, the raw faroffset shot displays sufficient frequencies of up to $70 \mathrm{~Hz}$. In comparison with the air gun, this can be explained by a sharper source impulse of the excited wavelet. In addition, the explosive charges were placed directly on the bottom of the pond, which resulted in a better coupling with the ground. We can also see an increase of frequencies with receiver depth. The faroffset shot lies topographically lower (about $170 \mathrm{~m}$ ) than the well head and the zero-offset shot. This elevation, which is mainly composed of unconsolidated hyaloclastite rock formations around the borehole, adds significant attenuation to waves propagating through them. Thus, fewer sideward oriented waves, with a shorter travel path (but later arrival times), are passing these shallow high-attenuating, rather unconsolidated zone, in comparison to the zero-offset shot. Deeper arrivals of waves which propagated through more consolidated formations, thus, suffer less from attenuation or scattering effects and maintain their higher frequency components. This is supported by the relatively deep apex of the first arrivals in the faroffset seismogram (Fig. 5).

Velocity profiles from first-break P- and S-wave arrivals show a strong gradient in the uppermost $1 \mathrm{~km}$ reflecting the relatively young and highly porous lava pile (Fig. 10). This agrees well with the crustal velocities of Iceland which also show a strong velocity gradient in the uppermost unconsolidated layers, where P-wave velocities can be as low as $1.6-2.0 \mathrm{~km} / \mathrm{s}$ and increase up to $3 \mathrm{~km} / \mathrm{s}$ (Flóvenz and Gunnarsson, 1991). In Fig. 10, the displayed interval velocities were smoothed using a 30-m spatial smoothing operator to remove scattering effects caused by a high trace sampling $(2.5 \mathrm{~m})$. Both P-and S-wave profiles follow the regional trend (Brandsdóttir et al., 1997) while generally higher velocities can be observed with increasing depth. Latter can be explained by the geothermal alteration and secondary mineralization causing the closure of cracks and pore space. The mean velocity along the borehole is about $4600 \mathrm{~m} / \mathrm{s}$ for the P- and $2700 \mathrm{~m} / \mathrm{s}$ for the S-waves. Several velocity anomalies are observed at 400,780 , and $980 \mathrm{~m}$ and coincide with high neutron-neutron counts indicating less porous formations, such as basaltic lava flows.

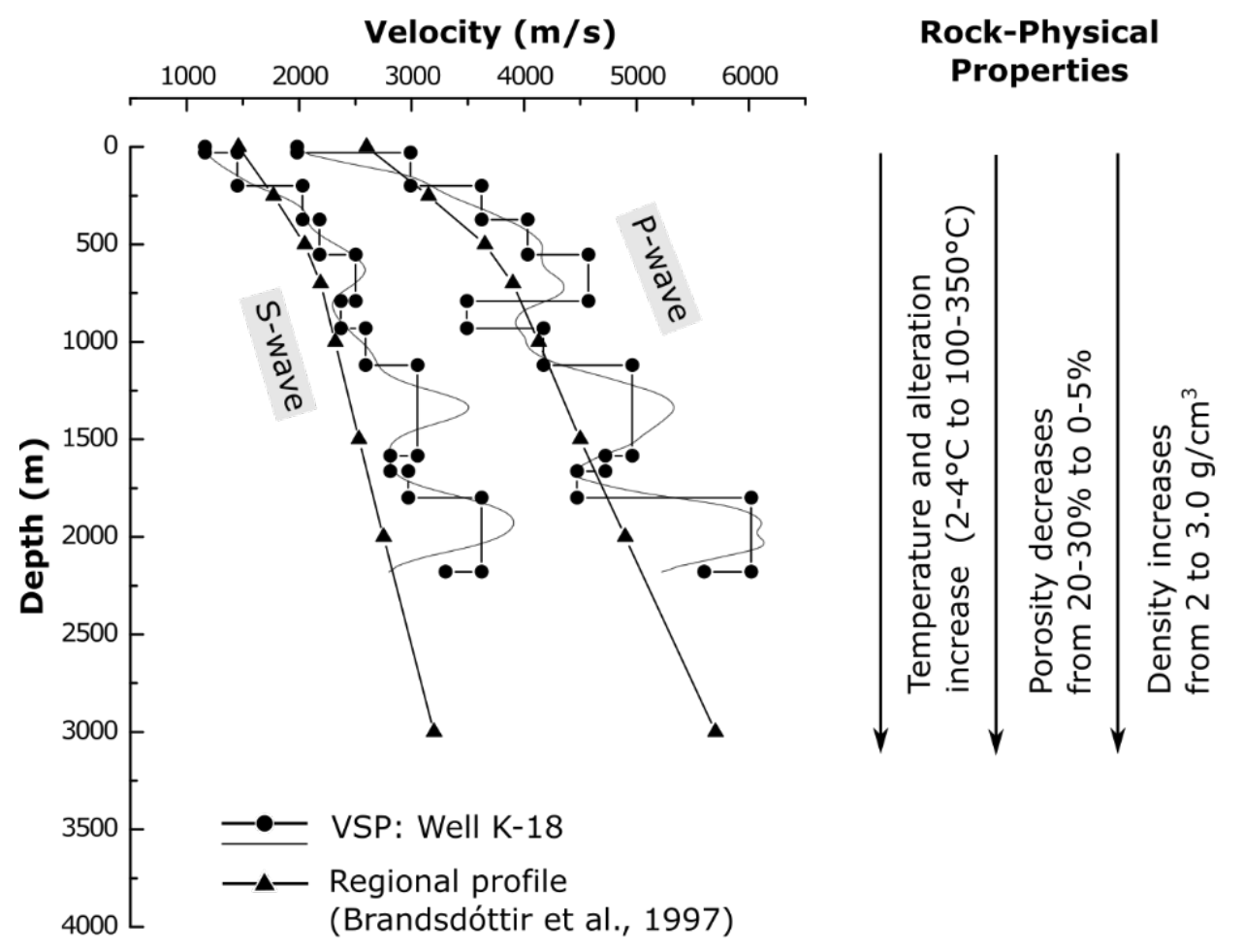

Figure 10. VSP velocity profiles in context with the generalized seismic structure of the Icelandic upper crust. Modified after Flóvenz and Gunnarsson (1991).

Fig. 11 shows the resulting seismograms of the source comparison of four zero-offset source configurations. As seen in this figure, the air gun provides significantly higher amplitudes with generally lower frequencies than the shot-hole explosive or detonating cord. Moreover, the summed air-gun shots have a slightly higher signal-to-noise ratio than the single shot due to 
destructive interference and suppression of incoherent noise. With respect to the actual spectral energy content (Fig. 12), the air gun provides generally higher energies in the low-frequency range, below $35 \mathrm{~Hz}$. In a transition zone between about 30 and $40 \mathrm{~Hz}$ all sources provide similar energies. At higher frequencies $(>40 \mathrm{~Hz})$, both shot-hole explosive and detonating cord display higher energies, up to $60 \mathrm{~Hz}$, than for the air gun.

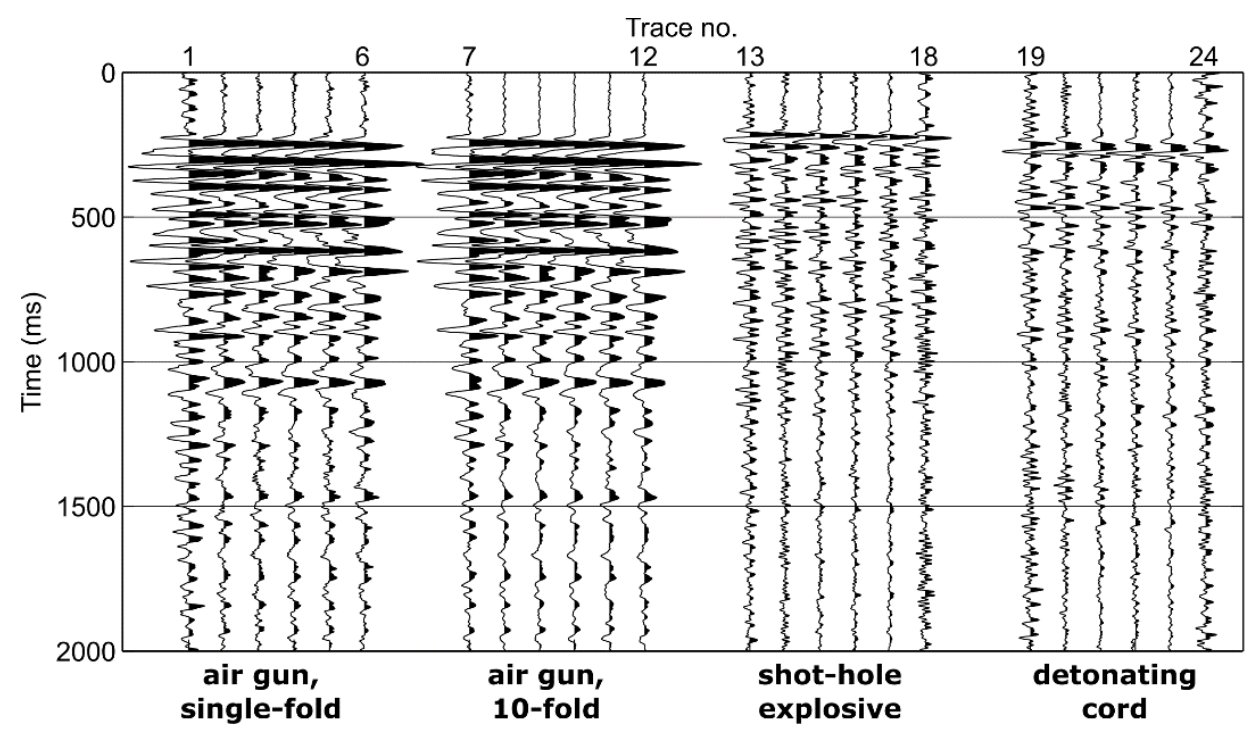

Figure 11. Zero-offset source comparison showing the vertical component of four common shot gathers at the same receiver positions, between 700 and $750 \mathrm{~m}$ depth. Each gather consists of six traces with a 10-m trace spacing. The traces are low-pass filtered and not scaled or normalized

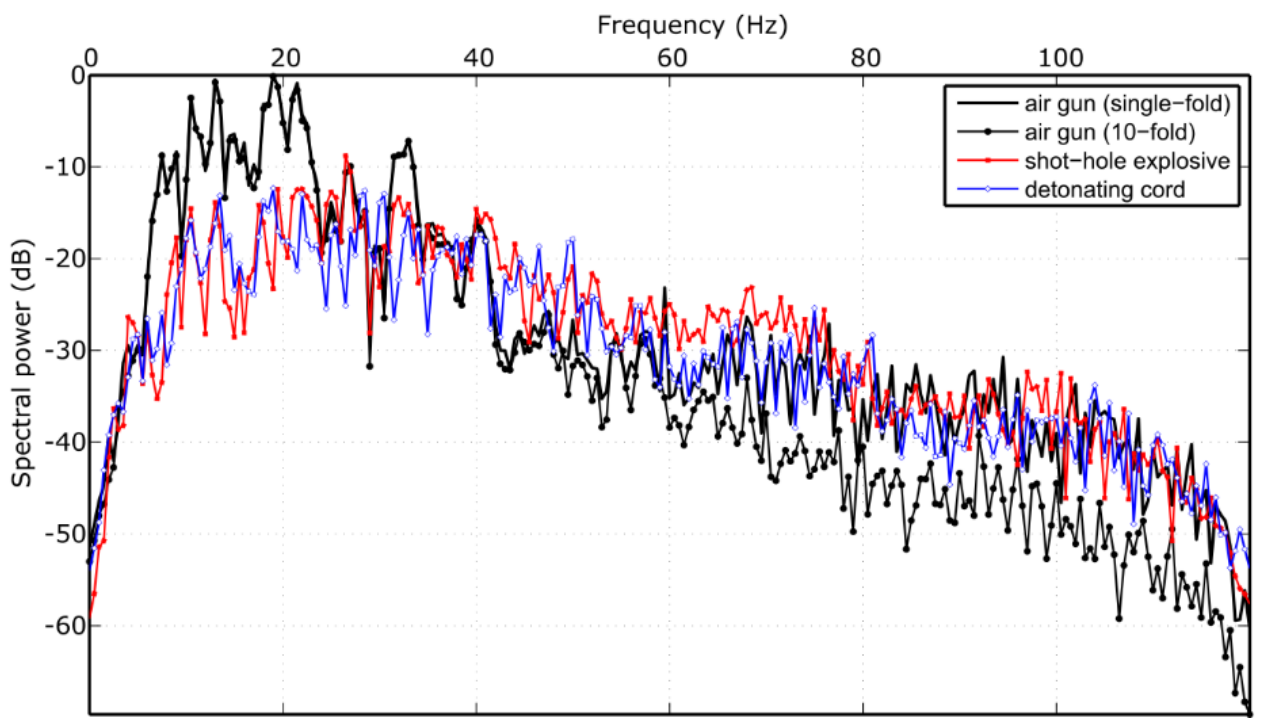

Figure 12. Zero-offset source comparison showing the power spectra of the shot gathers shown in Fig. 11.

Fig. 13 shows the result of the processed vertical component zero-offset shot compared with existing well log data. The decomposed upgoing wavefield emphasizes primary reflections (crossing the first arrivals) at early arrival times, along the borehole. Several multiples can be seen and are indicated by reflections parallel to the primary reflections, not crossing the first arrivals. Additionally, with help of the applied processing, the frequency content could be increased significantly to about 60-70 Hz, which further enhanced the vertical resolution of this seismic record. The processed seismic section (in two-way time), corridor stack, and log data are displayed at their logging depth, which is the measured depth above ground level. The depth-converted corridor stack clearly emphasizes primary reflections along the borehole, at depth. The stack (in time) furthermore provides an increased signal-to-noise ratio of about $40 \mathrm{~dB}$ (Fig. 14) compared to the brute surface seismic stack, which was calculated by summation of all air-gun shots recorded by the ancillary surface receiver array. The uppermost $1 \mathrm{~km}$ is characterized by a high-reflectivity zone, where the formation is also dominated by an alternating sequence of basaltic lavas and hyaloclastites. The strong reflection at $1.1 \mathrm{~km}$ marks the transition between a hyaloclastite sequence overlying an intruded basalt lava complex. Below $1.1 \mathrm{~km}$, reflection amplitudes diminish rapidly with depth. The reflection at about 1900 mdepthmay indicate the transition to the so called intrusive basement which begins at c. $1880 \mathrm{~m}$ (cf. Fig. 2) and is clearly 
seen in an increase of the sonic velocities and the P-wave velocities. It is interpreted to be a more massive dense intrusion probably representing a shallow, former gabbroic magma chamber of the Krafla volcano, now completely solidified. The apparently low reflection amplitude could be due to the low SNR and an incomplete (simplified) amplitude recovery. Although steeply dipping fracture zones and dykes are present in the area and also have been identified by geological mapping, they could not be observed from reflections in the zero-offset VSP data. Generally, they are difficult to image as they would act as wave guides introducing significant wave field complexities involving, for instance, ringing effects and distortion of reflections (Planke and Flóvenz, 1996). Also, due to the zero-offset shot geometry, potential reflections resulting from vertical and subvertical dipping faults are excluded during wavefield decomposition and, thus, not visible on the upgoing wavefield components. Furthermore, single fractures, as mapped for example by televiewer logs, are beyond the resolution limit of the recorded VSP data.

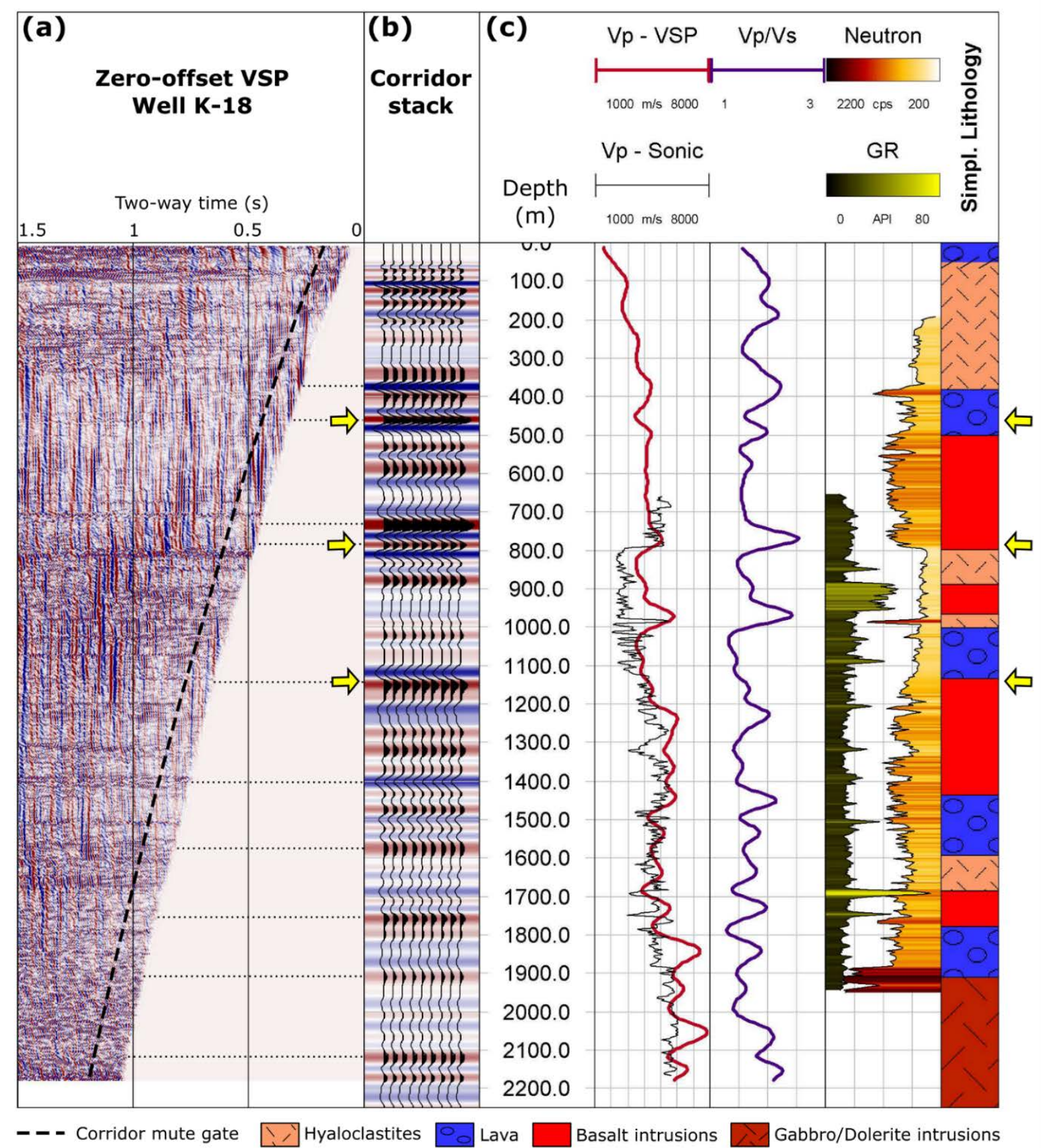

Figure 13. Results of the final processed one-component zero-offset VSP at well K-18. Shown are (a) the final processed upgoing wavefield, (b) the time-to-depth converted corridor stack, and (c) wireline logs, VSP velocity profile, and simplified lithology from drill cuttings. Yellow arrows mark dominant reflections along the well. Log data (sonic, natural gamma (GR), neutron-neutron, and lithology) courtesy of ísOR. 

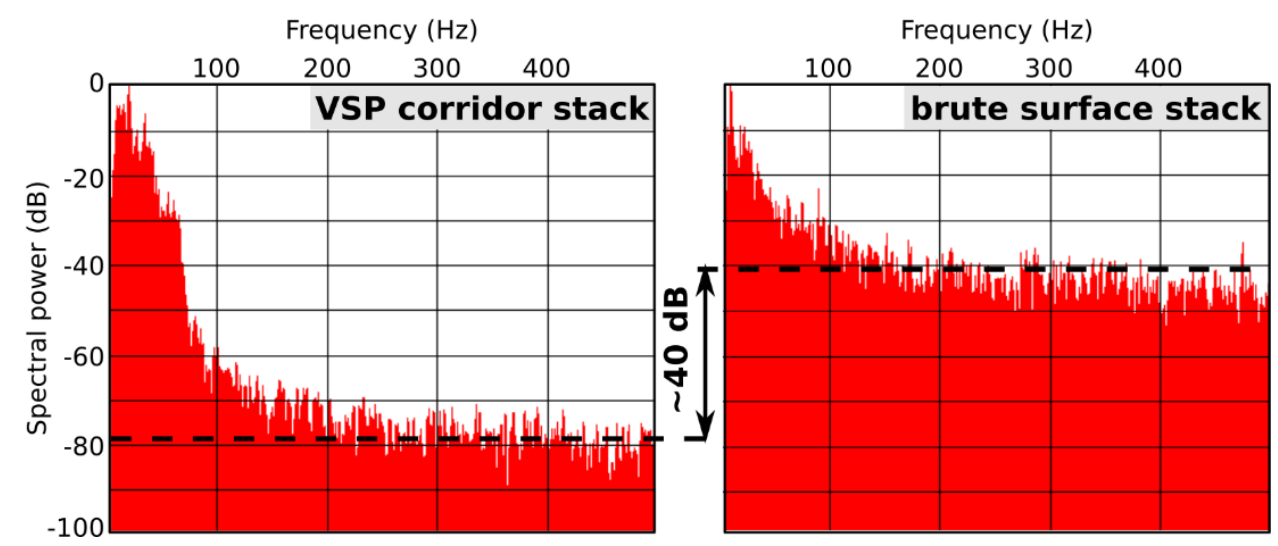

Figure 14. Comparison of power spectra of the final zero-offset VSP corridor stack and the brute surface stack. Latter was recorded with an eight-receiver geophone array placed between well $K-18$ and the zero-offset air-gun pit. Dashed lines indicate the approximate noise level the borehole.

Results of Kirchhoff depth migration and Fresnel volume migration of different input data sets are presented in Fig. 15. The 2D images clearly show an improved focusing and reduction of migration artifacts through application of both modeconstrained and focused migration methods. By Kirchhoff depth migration of the raw upgoing zero-offset wavefield, reflections smear largely along isochrones, which also include cross-talk events. Additional processing and extraction of the distinct wave modes further reduced these artifacts exhibiting reflections down to $1 \mathrm{~km}$ for PP and below 1-2 km for SS modes, around and along the borehole. Furthermore, FVM increased the focusing of reflection events providing similar results as for the mode-constrained Kirchhoff depth migration. The lateral extent of reflectors is reduced giving a good estimate of their true spatial position. Distinct reflections are predominately mapped along the well path and agree with changes in lithology of lava, hyaloclastite, and basaltic intrusions (cf. Figs. 2 and 13). 
(a)
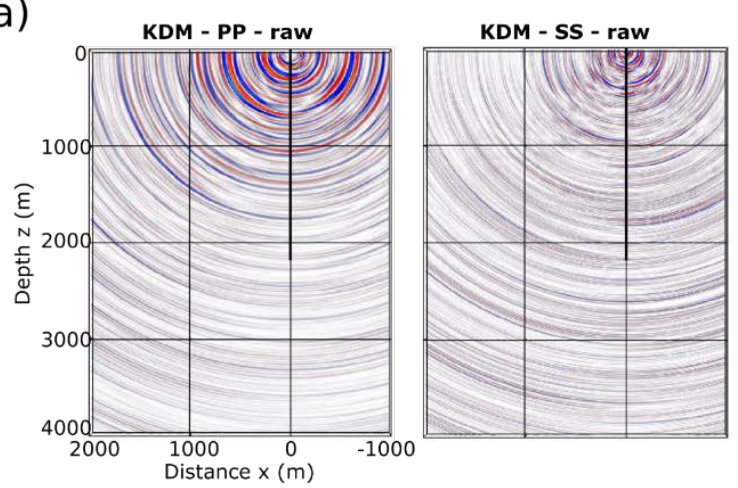

(b)

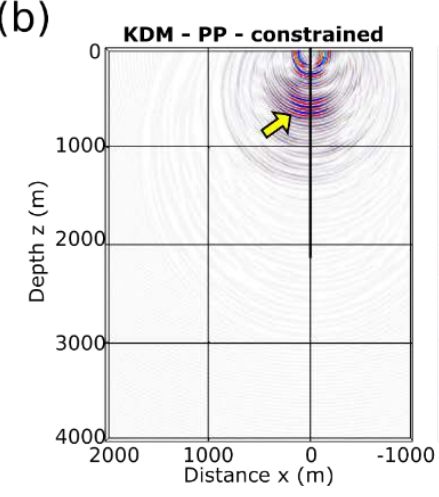

KDM - SS - constrained

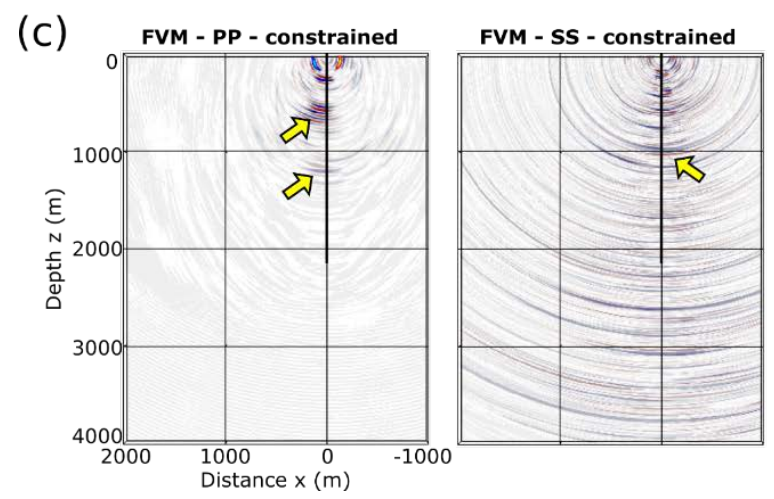

Figure 15. Comparison of migrated PP-and SS-reflection modes of the zero-offset shot, using (a) raw Kirchhoff depth migration (KDM), (b) mode-constrained Kirchhoff depth migration, and (c) mode-constrained Fresnel volume migration (FVM). 2D images extracted from the image volume. Yellow arrows mark some selected, dominant reflections.

Providing the best imaging results, the mode-constrained Fresnel volume migration were used for a final wave-modes stacked migration image (Fig. 16). As a result of the summation, coherent signal energy is amplified by superposition while migration noise or artifacts are reduced. Therefore, for zero- and far-offset VSP, each migration result of the four individual wave modes is summed and normalized into a final image. In the zero-offset data, we do not observe any dominant SP reflections. In the migrated SP modes, most amplitudes are distributed along the surface (upper image boundary), which can be explained by imaging artifacts due to cross talks. Consequently, the migrated SP mode was omitted from the final image. Fig. 16 displays the migrated VSP data in all three dimensions, within the boundaries of the predefined image grid (Fig. 9). Several reflectors are visible indicating potential impedance contrasts in the subsurface, which also agree with reflections seen from results of the zero-offset VSP (cf. Fig. 13). The dominant, hyperbolic character is still an effect of the insufficient source-receiver coverage. For the zero-offset source, distinct reflectors map along the well path and agree well with lithological key boundaries as also identified by the corridor stack (cf. Fig. 13) and the simplified lithological cross section (Fig. 2). Two major reflectivity zones are at about $400 \mathrm{~m}$ and between 750 and $900 \mathrm{~m}$. Below $1 \mathrm{~km}$, down to total borehole depth, reflectivity decreases while entering the rather homogenous intrusion dominated formations, already shown by the $1 \mathrm{C}$ zero-offset corridor. Furthermore, events are not well confined but also are distributed around the borehole. The spatial, or lateral, resolution of the reflection events increases with depth according to the Fresnel criteria. Deeper events, below the borehole, are seen especially from $2.2 \mathrm{~km}$ down to $3 \mathrm{~km}$, below the borehole. These events mainly result from SS migrated reflections and clearly indicate some deeper located impedance contrasts. The migrated far-offset shot displays less distinct reflections in the uppermost $2 \mathrm{~km}$. Instead, reflection amplitudes are more spread in space. Some steep dipping lineaments can be seen 
between one and two kilometers depth, laterally offset from the well. High-reflectivity zones are found at about 800, 1500, and below $2500 \mathrm{~m}$, directly below the extrapolated well path. Southwest, between the source position and the K-18 borehole, almost no reflections are visible in the migrated image. Here, the applied acquisition geometry is insufficient to illuminate shallow reflections. Moreover, transecting faults and fractures add additional scattering to the wavefield. A better imaging of this zone may be achieved by additional shot points of varying offsets as, for example, used by a walk-away VSP.
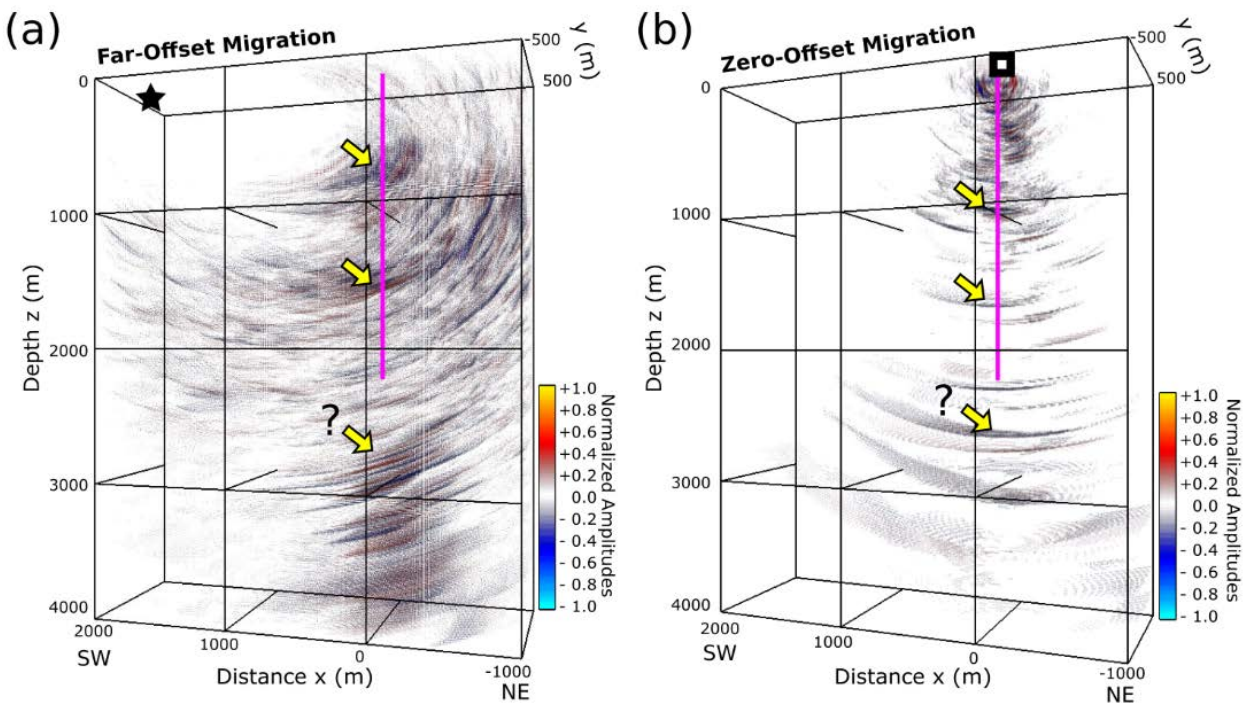

Figure 16. Results of the three-component mode-constrained Fresnel volume migration of the (a) far-and (b) zero-offset VSP. Images are in oblique view of the migrated and wave-mode stacked migration amplitudes using a constant $P$-and S-wave velocity model. Arrows mark dominant lithological boundaries, as indicated by strong migration amplitudes. For geometry setup, see also Fig. 9.

\section{Discussion}

Our results show that VSP surveying offers the chance to image subsurface structures in high-attenuating and scattering media, such as volcanic rocks where surface-based seismic methods (2D/3D profiling) often produce poor results. At Krafla, the signal-to-noise ratio of surface-to-well recordings lies in the $40 \mathrm{~dB}$ range. For small offsets, the application of an air gun close to the wellhead displays a good option in such geological backgrounds. For larger offsets (up to $2 \mathrm{~km}$ ), however, a single small-size air gun, as it was used in this study, may not provide a sufficient frequency range as, for example, reached with dynamite explosives.

In the present work, we considered a limited acquisition geometry, insofar as we have only included two shots, zero and far offset, with a low azimuthal coverage. With only these two source points available, the experiment is restricted, as the structural resolution/imaging of continuous reflectors is not guaranteed. Under these circumstances, however, it was possible to image steeply dipping events further away from the well. This justifies the potential use of this method, which would provide even better imaging results by using additional shot points for a better lateral resolution and higher subsurface sampling. Particularly for the zero-offset VSP, the radius of illumination is predominantly depth-dependent and can be estimated using the first Fresnel zone in a homogeneous medium, which in this case is limited to about 50-500 $\mathrm{m}$ around the borehole. The vertical resolution for the air-gun source is limited to about $125 \mathrm{~m}$ taking into account a P-wave velocity of about $5000 \mathrm{~m} / \mathrm{s}$ at $1000 \mathrm{~m}$ depth and a dominant frequency of about $20 \mathrm{~Hz}$ (of the unprocessed data). Latter, therefore, also suggests the use of geophones with a lower natural frequency in future surveys. For more powerful sources, such as explosives in a pond or shallow borehole, the vertical resolution limit decreases to about $80 \mathrm{~m}$ due to slightly higher signal frequencies of up to $40 \mathrm{~Hz}$ (Fig. 6). However, as shown for the zero-offset VSP, wavefield decomposition and VSP deconvolution techniques can significantly increase the frequency range of the data and thus the imaging resolution. At large offsets, depending on the subsurface stratigraphy, also a larger area may be sampled by reflected waves. The resultant wavefield, however, becomes more complicated with increasing complexity of the subsurface geology. Here, we expect a high degree of ray bending caused by the greater source offsets and high-velocity gradient which may entail an incomplete removal of the downgoing wavefield, before migration. Consequently, the resultant image is noisier and less focused including more artifacts compared to the much simpler zero-offset case, where the ray paths can be assumed to be near vertical and parallel to the borehole. 
The air gun as a zero-offset source, provides good results but also depends on the borehole depth and the coupling of the receivers to the borehole wall. At relatively shallow depths $(<1 \mathrm{~km})$, depending on the receiver coupling, the single-shot recordings may already provide high quality data (cf. Fig. 11). However, for the most parts of the borehole, several repeated shots at the same receiver position are necessary to maintain a good signal-to-noise ratio. Especially at greater depth, the number of repeated shots can exceed 15-20. Over several hundreds of meters this will significantly increase the overall acquisition time and, hence, costs of such a survey. We therefore have tested two additional zero-offset sources to assess their potential for imaging in volcanic, high-temperature environments. As shown the shot-hole explosives and detonating cord can improve the spectral bandwidth of the recorded signal, at moderate depths. At greater depths, however, the energy is insufficient for imaging deeper structures. In these cases, larger charges of dynamite are necessary with associated logistical and cost implications. Finally, in terms of environmental impact and repeatability, the use of non-destructive sources such as an air gun or vibrator (not available during this survey) may be favored over an explosive charge. Moreover, the use of shothole explosives is subject to problems like caving, abrasion, and altering of the surrounding rock at the bottom of the hole. For extensive surveys with some hundreds of shots, like in this VSP experiment, the shot hole will not withstand the repeated load. It also will change the radiation pattern due to progressive caving, which finally may even cause the collapse of the shot hole itself. In contrast, using a detonating cord can help reduce these effects but still have a stronger environmental impact. In terms of costs, however, it provides a good option for the rapid deployment of shallow to moderate check-shot surveys, down to c. $1 \mathrm{~km}$.

For the seismic migration, a constant velocity model for P- and S-waves based on the VSP velocity profiles was used. This is a strong simplification and not accurate since we observe changing P- and S-wave velocities with depth. Consequently, migrated images can only be used to estimate first-order reflections in the near-well surrounding. Along the borehole, the strongest velocity changes are observed in the uppermost $500 \mathrm{~m}$, especially for the P-waves. The resulting depth error correlates with the reflector depth and source offset, as the migration algorithm calculates travel times at each point in space for every source-receiver combination along the borehole (Fig. 17). For the zero offset, the relative error at deeper parts (in the borehole) is comparably small. That is why the geometry has only a small relative depth error, namely because of the fixed receiver positions and first-arrival times and the small distance between the foci (source, receiver) and the isochrones. The error increases with depth, especially below the well. Within the image area (cf. Fig. 9) and according to the regional velocity trend (cf. Fig. 10) we estimate the velocity error to be about 8 to $30 \%$, with respect to depth. Thus, for example, a reflector migrated at $3000 \mathrm{~m}$ depth may have a relative depth error of about 80 to $300 \mathrm{~m}$, below the deepest receiver position. In particular, later reflection amplitudes of the upper receiver positions may provide an erroneous contribution to the migration image. This effect is minimized (for PP, PS) by restricting the migration to recording times between first-arrival Pand S-waves (cf. Fig. 8). Generally speaking, the contribution of the uppermost levels of the deeper located reflections is low compared to levels close to the actual reflection point. This holds true for the zero-offset geometry. For the far offset, the travel time error increases because of the larger horizontal offset. In the migrated image, reflectors may therefore appear smeared and less focused due to insufficient stacking of isochrones. To provide an improved depth imaging for a detailed reflector interpretation, we therefore suggest a varying velocity model based on smoothed interval velocities and extrapolation below the borehole. Seismic tomography using also additional offset shots would also benefit the building of 3-D velocity model in this area.

(a)

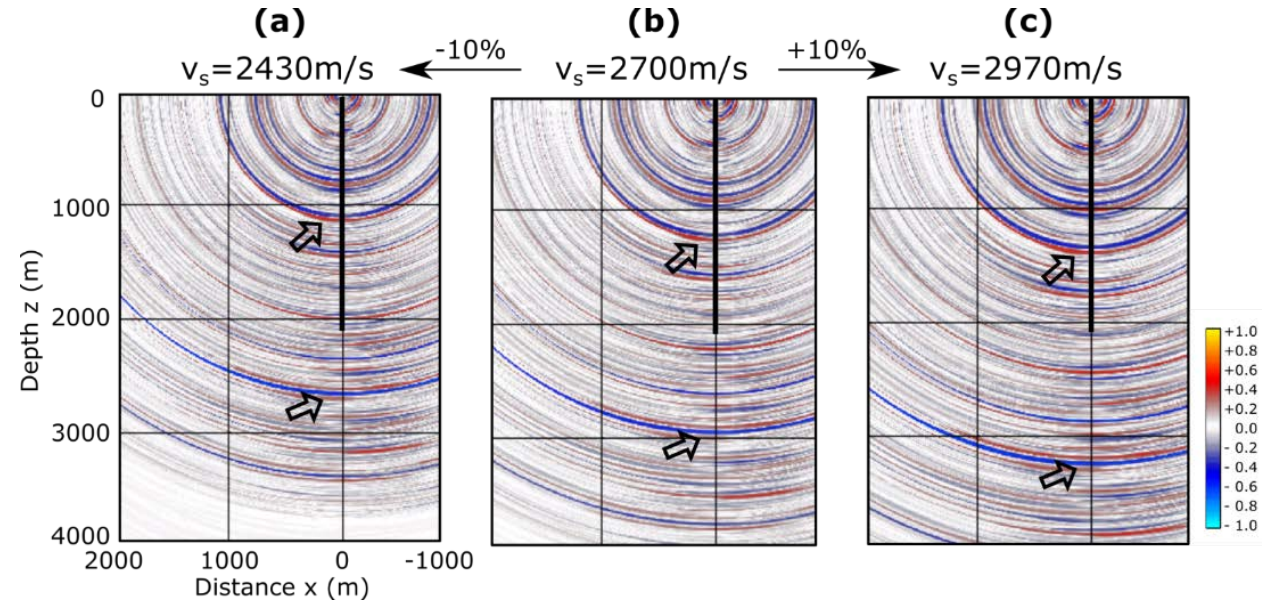

Figure 17. Influences of changing velocities on the migration result are exemplary shown for SS-migrated reflections of the zero-offset shot. The reference velocity model (b) is compared with a $10 \%$ decreased (a) and increased (c) velocity model, respectively. Arrows mark two dominant reflections, along and below the $K$-18 borehole. 
The main seismic reflectors, down to $1000 \mathrm{~m}$, are caused by alternating basalt flows and hyaloclastites. As seen in Fig. 13, reflections are particularly evident at interfaces between extrusive and intrusive formations. Below about $1000 \mathrm{~m}$, the reflectivity along well $\mathrm{K}-18$ decreases for $\mathrm{P}$ - and S-waves, as entering the intrusive/dike-dominated and rather homogeneous zone with weaker impedance contrasts compared to the overlying extrusive-dominated formations. In terms of vertical resolution, this experiment does not compare with wireline logs, such as sonic, gamma, neutron-neutron, or resistivity. Imaged features therefore, predominantly relate to lithological changes from different eruption series and the more massive intrusions.

With the help of seismic migration, we were able to look ahead of the well and map reflections at greater depths, where (to date) only few lithological information is available (cf. Fig. 2). Multiple reflections, from 2.2-3 km depth, which mostly result from S-wave reflections, are visible and may be explained by distributed or sheeted magma pockets fed by the deeper-rooted magma chamber. Evidence of magma at about 2.1 and $2.5 \mathrm{~km}$ depth in two nearby wells (Elders et al., 2011; Mortensen et al., 2010) supports this possibility. Furthermore, the brittle-ductile boundary in Krafla is located approximately at the same depth, as reports from passive seismic observations indicate (e.g., Blanck et al., 2017). These reports also show that the K-18 borehole is located outside of the seismogenic zone, where the majority of earthquakes were located. Hence, the actual depth of the brittle-ductile boundary directly below the borehole is unknown.

Despite the aforementioned limitations and data constraints, the here presented results provide rudimental constraints on the feasibility of the imaging potential of VSP for geothermal exploration in high-temperature volcanic geothermal fields.

\section{Conclusion}

We have presented results from a VSP experiment in the K-18 high temperature geothermal well at Krafla. This study comprises the first high-temperature VSP study of its kind on Iceland. The recorded borehole seismic data show an overall good data quality providing coherent first arrivals within a frequency range of 5-40 $\mathrm{Hz}$ using a single air gun for the zerooffset and dynamite explosives for the far-offset shots. By comparing different impulsive sources, we have shown that for the zero-offset VSP a detonating cord is a practicable source at moderate depths $(<1 \mathrm{~km})$ providing signals in a slightly higher frequency range (up to about $60 \mathrm{~Hz}$ ) than for the single air gun. At greater depths $(>1 \mathrm{~km}$ ), however, the air gun provides higher signal-to-noise ratios. Being fast, highly repeatable, and cost-efficient, it thus may be more suitable for a denselyspaced zero-offset survey. Higher frequencies, however, requires extended setups like air-gun arrays with increased working pressures and larger (deeper) pits. Data from two source locations, including zero and far offset, were processed using standard one-component processing and more comprehensive three-component migration techniques. Latter requires accurate knowledge of the distinct geophone components in order to correctly map reflections in depth and space. Both showed promising results and the ability to delineate key lithological boundaries such as lava, hyaloclastites, and intrusions along and below the borehole. Migration noise (artifacts) caused by the limited source-receiver coverage were successfully reduced by using Fresnel volume migration. In addition, by extracting and suppressing distinct wave modes, the final image of the zero-offset VSP was further enhanced.

We have shown that active seismic profiling is feasible in high-temperature volcanic fields, but also requires a careful survey planning and, if necessary, temperature control of the borehole and cooling by fluid injection during acquisition, while recording temporarily must be stopped. High-temperature geophone tools are essential in order to withstand high temperatures in the borehole and where cooling is not possible during acquisition. Optimized surveys as well as new processing and interpretation schemes are necessary in order to efficiently accommodate the specific requirements for geothermal exploration.

\section{Acknowledgments}

The research leading to these results has received funding from the European Community's Seventh Framework Program under grant agreement No. 608553 (Project IMAGE). We thank Landsvirkjun, the operator of the Krafla geothermal field, for technical and logistical support during the survey. We also thank the Operational Support Group of the International Continental Scientific Drilling Program (ICDP) for their technical support. We further acknowledge the support from the Research Council of Norway through its Centres of Excellence funding scheme, project 22372 (SP).

\section{References}

Árnadóttir, S., 2014. Results of Televiewer Logging in Well K-18 in Krafla High Temperature Area, NE-Iceland. Berkhout, A.J., 1982. Seismic migration: a. Theoretical Aspects. Elsevier Scientific Publishing Company. Biondi, B.L., 2005. 3-D seismic imaging. Soc. Explor. Geophys. https://doi.org/10.1190/1.9781560801689. 
Blanck, H., Ágústsson, K., Gunnarsson, K., 2017. Seismic monitoring in Krafla. November 2015 to November 2016. Tech. Report LV-2017-015.

Bodvarsson, G.S., Benson, S.M., Sigurdsson, O., Stefansson, V., Eliasson, E.T., 1984. The Krafla geothermal field, Iceland: 1. Analysis of well test data. Water Resour. Res. 20, 1515-1530.

Borm, G., Giese, R., 2003. Geophysical investigations: integrated seismic imaging system for geological prediction during tunnel construction. In: Kolymbas, D. (Ed.), Rational Tunneling Summer School, Innsbruck, 2003, (Advances in Geotechnical Engineering and Tunneling; 8). Logos Verlag, pp. 225-234.

Brandsdóttir, B., Menke, W., Einarsson, P., White, R.S., Staples, R.K., 1997. Färoe-Iceland ridge experiment 2. Crustal structure of the Krafla central volcano. J. Geophys. Res. Solid Earth 102, 7867-7886.

Buske, S., 1999. Three-dimensional pre-stack Kirchhoff migration of deep seismic reflection data. Geophys. J. Int. 137:243260. https://doi.org/10.1046/j.1365-246X.1999.00789.x.

Buske, S., Gutjahr, S., Sick, C., 2009. Fresnel volume migration of single-component seismic data. Geophysics 74, WCA47WCA55.

Cameli, G.M., Batini, F., Dini, I., Lee, J.M., Gibson Jr., R.L., Toksöz, M.N., 1995. Seismic delineation of a geothermal reservoir in the Monteverdi area from VSP data. Proceedings of the World Geothermal Congress, pp. 821-826.

Chopra, S., Blias, E., Manerikar, A., Kryzan, A., Chavina, L., Alexeev, V., Larsen, G., 2002. Simultaneous acquisition of 3D surface seismic and 3D VSP data - processing and integration. 72nd Ann. Internat. Mtg https://doi.org/10.1190/1.1817183.

Christie, P., Ireson, D., Rutherford, J., Smith, N., Dodds, K., Johnston, L., Schaffner, J., 1995. Borehole seismic data sharpen the reservoir image. Oilf. Rev. 4, 18-31.

DiSiena, J.P., Gaiser, J.E., Corrigan, D., 1984. Three-component vertical seismic profiles; orientation of horizontal components for shear wave analysis. Vert. Seism. Profiling, Part B Adv. Concepts, pp. 189-204.

Einarsson, P., 1978. S-wave shadows in the Krafla caldera in NE-Iceland, evidence for a magma chamber in the crust. Bull. Volcanol. 41, 187-195.

Elders, W.A., Friðleifsson, G.Ó., Zierenberg, R.A., Pope, E.C., Mortensen, A.K., Guðmundsson, Á., Lowenstern, J.B., Marks, N.E., Owens, L., Bird, D.K., et al., 2011. Origin of a rhyolite that intruded a geothermal well while drilling at the Krafla volcano, Iceland. Geology 39, 231-234.

Flóvenz, Ó.G., Gunnarsson, K., 1991. Seismic crustal structure in Iceland and surrounding area. Tectonophysics 189, 1-17.

Gray, S.H., Etgen, J., Dellinger, J., Whitmore, D., 2001. Seismic migration problems and solutions. Geophysics 66, $1622-1640$.

Hackert, C.L., Parra, J.O., 2002. Calibrating well logs to VSP attributes: interval velocity and amplitude. Lead. Edge 21:52-57. https://doi.org/10.1190/1.1445848.

Hagedoorn, J.G., 1954. A process of seismic reflection interpretation. Geophys. Prospect. 2, 85-127.

Halldórsdóttir, S., Erlendsson, Ö., Hersir, G.P., Gunnarsson, K., Blischke, A., Helgadóttir, H.M., Árnadóttir, S., Blanck, H., Kästner, F., Planke, S., 2014. Vertical seismic profiling (VSP) experiment in Krafla. NE-Iceland Field Report - Summary of Operations from May to June 2014.

Hardage, B.A., 2000. Vertical Seismic Profiling: Principles (Pergamon).

Hendrick, N., Hearn, S., 1999. Polarisation analysis: what is it? Why do you need it? How do you do it? Explor. Geophys. 30, 177-190.

Hinds, R.C., Anderson, N.L., Kuzmiski, R.D., 1996. VSP Interpretive Processing. Society of Exploration Geophysicists. https://doi.org/10.1190/1.9781560801894.

Hjartardóttir, Á.R., Einarsson, P., Bramham, E., Wright, T.J., 2012. The Krafla fissure swarm, Iceland, and its formation by rifting events. Bull. Volcanol. 74, 2139-2153.

Hloušek, F., Hellwig, O., Buske, S., 2015. Three-dimensional focused seismic imaging for geothermal exploration in crystalline rock near Schneeberg, Germany. Geophys. Prospect. 63 (4):999-1014. https://doi.org/10.1111/1365-2478.12239.

Kästner, F., 2015. Vertical Seismic Profiling in the Krafla Geothermal Field. TU Bergakademie Freiberg, NE-Iceland.

Lorenzo, C., Soto, J., Palma, H., Diez, H., Pérez, H., 2015. Vertical seismic profile (VSP) in injection well AZ-03, Los Azufres geothermal field, México. World Geotherm. Congr. 2015.

Lüth, S., Buske, S., Giese, R., Goertz, A., 2005. Fresnel volume migration of multicomponent data. Geophysics 70, S121-S129.

Menke, W., West, M., Brandsdóttir, B., Sparks, D., 1998. Compressional and shear velocity structure of the lithosphere in northern Iceland. Bull. Seismol. Soc. Am. 88, 1561-1571.

Millett, J.M., Wilkins, A.D., Campbell, E., Hole, M.J., Taylor, R.A., Healy, D., Jerram, D.A., Jolley, D.W., Planke, S., Archer, S.G., Blischke, A., 2016. The geology of offshore drilling through basalt sequences: understanding operational complications to improve efficiency. Mar. Pet. Geol. 77:1177-1192. https://doi.org/10.1016/j.marpetgeo.2016.08.010.

Millett, J.M., Planke, S., Kästner, F., Blischke, A., Hersir, G.P., Halldórsdóttir, S., Flóvenz, Ó.G., Árnadóttir, S., Helgadóttir, H.M., Vakulenko, S., Burjak, S., Erlendsson, Ö., Gunnarsson, K., Giese, R., Paris, J.C., Jerram, D., Stefánsson, H.Ö., Blanck, H., Júlíusson, E., 2018. Subsurface geology and velocity structure of the Krafla high temperature geothermal field, Iceland: integrated ditch cuttings, wireline and zero offset vertical seismic profile analysis. J. Volcanol. Geotherm. Res.

Mortensen, A.K., Guðmundsson, Á., Steingrímsson, B., Sigmundsson, F., Axelsson, G., Ármannsson, H., Björnsson, H., Ágústsson, K., Sæmundsson, K., Ólafsson, M., Karlsdóttir, R., Halldórsdóttir, S., Hauksson, T., 2009. Jarðhitakerfið í Kröflu. Samantekt rannsókna á jarđhitakerfinu og endurskođađ hugmyndalíkan.

Mortensen, A.K., Grönvold, K., Gudmundsson, Á., Steingrímsson, B., Egilson, P., 2010. Quenched silicic glass from well KJ-39 in Krafla, North-Eastern Iceland. Proc. World Geotherm. Congr, pp. 25-29.

Nakagome, O., Uchida, T., Horikoshi, T., 1998. Seismic reflection and VSP in the Kakkonda geothermal field, Japan: fractured reservoir characterization. Geothermics 27, 535-552.

Nielsen, G., Maack, R., Gudmundsson, A., Gunnarsson, G.I., 2000. Completion of Krafla geothermal power plant. Proc. World Geothermal Congress. 
Onacha, S., Kahn, D., Malin, P., Shalev, E., 2005. Resistivity and microearthquake imaging of Krafla geothermal field, NE Iceland. Trans. Geotherm. Resour. Counc. 29, 497-502.

Payne, M.A., Eriksen, E.A., Rape, T.D., 1994. Considerations for high-resolution VSP imaging. Lead. Edge 13 (3):173-180. https://doi.org/10.1190/1.1437010.

Place, J., Diraison, M., Naville, C., Géraud, Y., Schaming, M., Dezayes, C., 2010. Decoupling of deformation in the Upper Rhine Graben sediments. Seismic reflection and diffraction on 3-component Vertical Seismic Profiling (Soultz-sous-Forêts area). Compt. Rendus Geosci. 342:575-586. https://doi.org/10.1016/j.crte.2010.01.001.

Place, J., Sausse, J., Marthelot, J.M., Diraison, M., Géraud, Y., Naville, C., 2011. 3-Dmapping of permeable structures affecting a deep granite basement using isotropic 3C VSP data. Geophys. J. Int. 186:245-263. https://doi.org/10.1111/j.1365246X.2011.05012.x.

Planke, S., Cambray, H., 1998. 38. Seismic properties of flood basalts from hole 917A downhole data, southeast Greenland volcanic margin. Proc. Ocean Drill. Program Sci. Results 152, 453-462.

Planke, S., Flóvenz, O.G., 1996. Seismic properties of flood basalts. Norw. Pet. Soc. Conference on Seismic Lithology.

Planke, S., Symonds, P.A., Alvestad, E., Skogseid, J., 2000. Seismic volcano-stratigraphy of large-volume basaltic extrusive complexes on rifted margins. J. Geophys. Res. Solid Earth 105, 19335-19351.

Poletto, F., Corubolo, P., Farina, B., Schleifer, A., Petronio, L., Della Vedova, B., 2013. Multi-offset VSP for the integrated geophysical characterization of the Grado (NE Italy) carbonatic reservoir. European Geothermal Congress 2013, p. 7.

Reinsch, T., Henninges, J., Götz, J., Jousset, P., Bruhn, D., Lüth, S., 2015. Distributed acoustic sensing technology for seismic exploration in magmatic geothermal areas. World Geotherm. Congr. 2015, pp. 1-5.

Reiser, F., Schmelzbach, C., Maurer, H., Greenhalgh, S., Hellwig, O., 2017. Optimizing the design of vertical seismic profiling (VSP) for imaging fracture zones over hard-rock basement geothermal environments. J. Appl. Geophys. 139, $25-35$.

Riedel, M., Dutsch, C., Alexandrakis, C., Dini, I., Ciuffi, S., Buske, S., 2015. Seismic depth imaging of a geothermal system in southern Tuscany. Geophys. Prospect. 63 (4): 957-974. https://doi.org/10.1111/1365-2478.12254.

Sausse, J., Dezayes, C., Dorbath, L., Genter, A., Place, J., 2010. 3D model of fracture zones at Soultz-sous-Forêts based on geological data, image logs, induced microseismicity and vertical seismic profiles. Compt. Rendus Geosci. 342:531-545. https://doi.org/ 10.1016/j.crte.2010.01.011.

Schmelzbach, C., Greenhalgh, S., Reiser, F., Girard, J.-F., Bretaudeau, F., Capar, L., Bitri, A.,2016. Advanced seismic processing/imaging techniques and their potential for geothermal exploration. Interpretation 4:SR1-SR18. https://doi.org/10.1190/INT-2016-0017.1.

Schneider, W.A., 1978. Integral formulation for migration in two and three dimensions. Geophysics 43, 49-76.

Sheriff, R.E., 2002. Encyclopedic dictionary of applied geophysics. Geophysical References, 4th ed. Society of exploration geophysicists, Tulsa, OK.

Staples, R.K., White, R.S., Brandsdóttir, B., Menke, W., Maguire, P.K.H., McBride, J.H., 1997. Färoe-Iceland Ridge Experiment 1. Crustal structure of northeastern Iceland. J. Geophys. Res. Solid Earth 102:7849-7866. https://doi.org/10.1029/96JB03911.

Stewart, R.R., 2001. VSP: an in-depth seismic understanding. CSEG Rec, pp. 79-83.

Tang, C., Rial, J.A., Lees, J.M., 2008. Seismic imaging of the geothermal field at Krafla, Iceland using shear-wave splitting. J. Volcanol. Geotherm. Res. 176, 315-324. Thordarson, T., Höskuldsson, Á., 2002. Iceland. Terra Publishing.

porsteinsdóttir, U., 2017. A 3D geological static field model of the Krafla geothermal area. NE-Iceland; Constructing a Workflow Applied to the Pico Alto Geothermal Area, Azores. University of Iceland.

Weisenberger, T., Axelsson, G., Arnaldsson, A., Blischke, A., Óskarsson, F., Ármannsson, H., Blanck, H., Helgadóttir, H.M., Berthet, J.C., Árnason, K., Ágústsson, K., Gylfadóttir, S., Guđmundsdóttir, V., 2015. Revision of the Conceptual Model of the Krafla Geothermal System.

Wohletz, K., Heiken, G., 1992. Volcanology and Geothermal Energy. University of California Press, Berkeley. 